\title{
Mechanical behaviour of unsaturated marine sediments: experimental and theoretical approaches
}

\author{
E. Vanoudheusden, N. Sultan* and P. Cochonat
}

IFREMER Brest, Departement de Geosciences Marines, Technopole de Brest-Iroise, B.P. 70, Plouzané F-29280, France

*: Corresponding author : Tel.: +33 2982242 59; fax: +33 2982245 70. nabil.sultan@ifremer.fr

\begin{abstract}
The COSTA target areas exhibit different slope failure events, which reflect different triggering mechanisms including gas hydrates dissociation. Gas hydrates stability law depends on temperature, pore pressure, gas chemistry, and pore water salinity. Any change in the equilibrium parameters may convert the hydrate to gas plus water, causing significant weakening of the sediment, and generating a rise of pore pressure. A significant consequence of the hydrate melting is the gas production, which alters significantly the behaviour and mechanical properties of the marine sediments and could be very hazardous when the sediment is unloaded in undrained conditions.

The behaviour of the unsaturated marine sediment has to be accurately identified in order to quantify the geological risks associated to the hydrate dissociation [see, for instance, Sultan, N., Cochonat, P., Foucher, J.P., Mienert, J., this volume. Effect of gas hydrates melting on seafloor slope instability]. Thus, in this work, five tests were carried out on synthetic marine sediments in order to identify the gas effect on the hydro-mechanical behaviour of unsaturated marine sediments. Based on the experimental results obtained from this study, on previous constitutive models [Alonso, E.E., Gens, A., Josa A., 1990. A constitutive model for partially saturated soils. Géotechnique 40(3), 405-430; Gens, A., Alonso, E.E., 1992. A framework for the behaviour of unsaturated expansive clays. Can. Geotech. J. 29, 1013-1032] and on the relationship of Van Genuchten [Van Genuchten, M.Th., 1980. A closedform equation for predicting the hydraulic conductivity of unsaturated soils. Soil Sci. Soc. Am. J. 44, 892-898], a new mathematical formulation was proposed to simulate the behaviour of the unsaturated soil. Qualitative comparison between experimental results and model predictions shows the capacity of the proposed model to reasonably reproduce the essential features of the hydro-mechanical behaviour of marine unsaturated sediment. Experimental and simulation results show that unloading (tidal cycles, erosion, natural slope instabilities, excavation) a submarine unsaturated sediment slope in shallow water is much more hazardous than unloading the same submarine slope in deep water.
\end{abstract}

Keywords: unsaturated sediment; capillary pressure; triaxial tests; undrained behaviour; shear strength 


\section{Introduction}

Temperature and/or pressure changes can modify the gas hydrate equilibrium conditions and induce gas production. Gas may alter significantly the behaviour and mechanical properties of the marine soils. For high water degrees of saturation gas bubbles are in an occluded zone within the pore fluid. For this high degree of saturation, the principle of effective stress remains valid. However, in addition to the effective stress theory, the gas compressibility (Boyle's law ) and the gas solubility (Henry's law) must be considered (see for instance Atigh \& Byrne 2003). For lower degrees of saturation where the gas and water phases are continuous, the effective stress theory is not valid (see for instance Coleman 1962, Matyas \& Rahakrishna, 1968 and Fredlund \& Morgenstern 1977) and it is essential to consider the following three state variables: 1) mean net stress (difference between mean stress and pore gas pressure) 2) the matric suction (difference between pore gas pressure and pore water pressure) and 3) deviator stress.

In marine domain, sediments with low degree of saturation (or high gas content) could be met in the vicinity of dissociating hydrate. Figure 1-a shows the in-situ measurement, using the Ifremer piezocone (Meunier et al. 2003), of the $\mathrm{P}$ wave velocity as a function of depth in the vicinity of gas hydrates occurrence zone. Figure 1-a shows low values of the P wave velocity measured between $10 \mathrm{~m}$ and $15 \mathrm{~m}$ below the seafloor, which correspond to sediment with low degree of saturation (around $84 \%$ - Figure 1-b). For this type of unsaturated sediment, the Alonso et al. and Gens et al. models (Alonso et al. 1990 et Gens et al. 1992) can be accurately used to predict the hydro-mechanical behaviour. Recently several authors (Cui et al. 1995, Cui and Delage 1996, Pietruszczak and Pande 1996 among other) have used the capillary pressure as a stress state variable in order to describe the behaviour of unsaturated soil under different hydro-mechanical loadings. In general, those models have extended the Cam-clay 
model for isotropic unsaturated soil. Cui et al. (1995) proposed an analytical expression of the yield curve, which allows to include the initial anisotropy of the natural soil.

The constitutive model of Alonso et al. is able to predict the volumetric strains and shear strains for any stress paths under drained conditions. However, it cannot be used to predict the behavior during undrained paths because it doesn't provide any information on the variation of degree of saturation (Wheeler 1996 and Wheeler et al. 2003). In order to take into account the behavior of unsaturated soil during sudden unloading (undrained conditions), additional equations considering the change of degree of saturation during different stress paths have to be included in the Alonso et al. model (see for instance Wheeler et al. 2003 and Sheng et al. 2004).

In this work, the unsaturated marine sediment behaviour has been first investigated in the laboratory. A new experimental apparatus was developed to control separately the different stress state variables, which characterize the behaviour of an unsaturated marine sediment. A series of experimental tests were conducted in order to identify the main features behaviour of a synthetic unsaturated soil. The obtained results were essential to the development of a new constitutive model where a special attention was devoted to the sediment behaviour under undrained conditions reproducing the behaviour at short term of marine sediment with low permeability preventing water and gas drainage.

\section{Special triaxial cell for unsaturated soil}

In order to examine the hydro-mechanical behaviour of unsaturated marine sediment, we have developed a new triaxial cell. This special apparatus allows distinct control of the pore-water and pore-gas pressures. The experimental device is based on the standard axis translation method in which the gas and water pressures are controlled independently allowing full control of the gas-water pressure difference. In a porous medium, the contact between two fluids induces a discontinuity of the pressure at the interface separating the two fluids. This 
discontinuity of pressure is called the capillary pressure $p_{c}$. Therefore $p_{c}$ is equal to the difference between the two pressures of those fluids. This capillary pressure is given by the Kelvin equation:

$$
p_{c}=\frac{2 \sigma \cos \theta}{r}
$$

where $\sigma$ is the interfacial tension between the two fluids, $\theta$ is the contact angle between the two fluids and $r$ is the pore radius.

In order to apply a capillary pressure on the soil sample, different experimental techniques can be used. In this study, the porous plate method, also called axis translation method is used. The sample is saturated with gas and water. The method consists of bringing to bear two different pressures on both fluids using a ceramic porous stone. The main characteristic of this porous stone is its very small diameter pores, and consequently (see Equation 1) the high capillary pressure, which can be imposed between the two fluids. The disadvantage of this method is the test duration, which can be very long due to the low permeability of the porous stone.

The mechanical tests including capillary pressure control were carried out using the special triaxial cell presented in Figure 2. The soil sample $(5 \mathrm{~cm}$ of diameter, $10 \mathrm{~cm}$ in height), contained into a membrane, is placed on a ceramic porous stone, which allows the free movement of water, but not gas, through it (in the limit of its capillary pressure). The bottom of the sample is connected to a pressure generator, which maintains the pressure of water inside the sample and control the water volume. At the top plate of the sample is applied the gas pressure. The confining pressure is imposed by a pressure generator (GDS), which allows the control of the confining pressure and the water volume surrounding the sample. In order to carry out the hydro-mechanical tests by controlling the capillary pressure, two conditions must be ensured: 
- $\quad \mathrm{u}_{\mathrm{g}}>\mathrm{u}_{\mathrm{w}}$ to prevent water passing into the gas pressure generator.

- $\quad \mathrm{u}_{\mathrm{g}}<\mathrm{u}_{\mathrm{w}}+\mathrm{p}_{\mathrm{c}}$ to prevent gas passing through the ceramic porous stone.

The axial stress is imposed by a piston pushed down from a mechanical frame. The vertical strain is determined from the displacement of the piston (Figure 2).

\section{Soil properties}

In the following, the same marine sediment (silty clay) has been used for all the laboratory tests (Null Tests and hydro-mechanical test). The Atterberg limit tests carried out on the studied sediment show a liquid limit of $215 \%$ and a plastic limit of $106 \%$, resulting in a plasticity index of $109 \%$. The initial void ratio was around 6.2 (porosity of 0.86 ). The Cc coefficient (compressibility coefficient $=1)$, the Cs coefficient $($ swelling coefficient $=0.1)$ and the preconsolidation pressure $(=20 \mathrm{kPa})$ were determined from oedometer test carried out on saturated marine sediment. For the oedometer test and at each step loading, the consolidation coefficient and the permeability coefficient were determined. Oedometer test results are summarized in Table 2.

\section{Stress state variables for unsaturated soil}

Terzaghi, in 1927, defined effective stress controlling the volume changes of saturated soils, as the total mean stress minus the pore water pressure. Afterwards the concept of effective stress has been extended to other porous materials by Biot (1941), whose work formed the basis of all further developments on the coupled hydromechanical behaviour of porous materials. The extension of the effective stress concept to a porous solid containing two fluids has been tentatively made by Bishop (1959), for unsaturated soils containing water and air. Later, it was shown that this extension was unable to predict the behaviour of unsaturated soil (Jennings \& Burland 1962). 
Studies on the volume change behaviour of unsaturated soils showed subsequently (Coleman 1962) that the complete definition of the stress state of unsaturated soils required the definition of two stress variables : the total mean net stress $\sigma_{m}-u_{\mathrm{g}}$ and the capillary pressure $p_{c}=u_{\mathrm{g}}-u_{\mathrm{w}}$ (in which $\sigma_{m}$ is the total mean stress and $u_{\mathrm{g}}$ and $u_{\mathrm{w}}$ respectively are the gas and water pressures).

Based on experimental results, Fredlund and Morgenstern (1977) have shown that the stress state variables, governing the behaviour of an unsaturated soil, consist of two of the three possible combinations of the three isotropic tensors $\left(\underline{\sigma}, \mathrm{u}_{\mathrm{w}} \underline{1}\right.$ and $\left.\mathrm{u}_{\mathrm{g}} \underline{1}\right)$ :

1) $\left(\underline{\sigma}-\mathrm{u}_{\mathrm{w}} \underline{1}\right)$ and $\left(\mathrm{u}_{\mathrm{g}}-\mathrm{u}_{\mathrm{w}}\right) \underline{1}$

2) $\left(\underline{\sigma}-u_{g} \underline{1}\right)$ and $\left(u_{g}-u_{w}\right) \underline{1}$

3) $\left(\underline{\sigma}-\mathrm{u}_{\mathrm{g}} \underline{1}\right)$ and $\left(\underline{\sigma}-\mathrm{u}_{\mathrm{w}} \underline{1}\right)$

where $\underline{\sigma}$ is the stress tensor, $u_{w}$ is the water pressure value inside the sample, $u_{g}$ is the gas pressure value inside the sample and $\underline{1}$ is the tensor unit.

In their unsaturated tests, Fredlund and Morgenstern (1977) increased simultaneously the isotopic stress tensor, the water and air pressures in the sample with equal increments $\left(\Delta \underline{\sigma}=\Delta \mathrm{u}_{\mathrm{w}} \underline{\mathbf{1}}=\Delta \mathrm{u}_{\mathrm{g}} \underline{1}\right)$. No change of the sample and the pore water volumes were observed. They concluded that this absence of volume change was due to the constant values of the stress variables which are $\Delta\left(\underline{\sigma}-\mathrm{u}_{\mathrm{w}} \underline{\mathbf{1}}\right)=\Delta\left(\mathrm{u}_{\mathrm{g}}-\mathrm{u}_{\mathrm{w}}\right) \underline{\mathbf{1}}=\Delta\left(\underline{\sigma}-\mathrm{u}_{\mathrm{g}} \underline{\mathbf{1}}\right)=0$. These tests were called Null Tests.

In order to validate the experimental procedures of our project, three Null Tests were carried out on the same soil sample. The summary of the stress conditions and the tests results are presented in Table 3. The sample was first saturated under a mean effective pressure of $300 \mathrm{kPa}$ (confining pressure equals $500 \mathrm{kPa}$ ). The gas was then introduced into the sample at $280 \mathrm{kPa}$. Once the equilibrium was reached, gas, confining water and pore water pressures were increased or decreased by the same value (see "pressure increment" column in Table 3). 
Figure 3, Figure 4 and Figure 5 present the pore water volume change and the confining water volume change under an increment loading $\left(\Delta \sigma_{3}=\Delta \mathrm{u}_{\mathrm{w}}=\Delta \mathrm{u}_{\mathrm{g}}\right)$ of $1:+45 \mathrm{kPa}, 2:+38 \mathrm{kPa}$ and 3 : $-183 \mathrm{kPa}$.

For the NT1 test and after 17 hours, it can be observed that only a total volume change of around $0.011 \%$ and a water volume change of around $0.014 \%$ were observed (Figure 3). For the NT2 test, after 70 hours, the total volume change was $0.028 \%$, and the water volume change $0.048 \%$ (Figure 4). Finally, for the NT3 test that last more than 170 hours, the maximum total volume change monitored was only $0.032 \%$, and the maximum water volume change $0.026 \%$ (Figure 5). We can note that the sinusoidal volumes variations may be due to the temperature.

To conclude, under constant stress state variables, the total and water volume changes of the marine soil sample (Figure 3 through Figure 5) were less than $0.05 \%$. Therefore the considered stress state variables (total mean net stress and capillary pressure) are relevant to describe the volume behaviour of an unsaturated soil.

\section{Hydro-mechanical properties of unsaturated soil : experimental results}

In order to identify the unsaturated sediments behaviour, five triaxial tests have been carried out on a synthetic marine soil using the cell described in paragraph 2. A fresh sample of the same marine sediment was used for each test. The shearing of the sample was obtained by an increase of the axial stress $\sigma_{1}$ using the mechanical piston.

The stress paths have been diversified to determine the main features of the unsaturated soil behaviour and the evolution of the shear resistance of this marine sediment with capillary pressure. Three triaxial tests were carried out at constant capillary pressure (drained conditions) and two at constant water content (undrained conditions). 


\subsection{Test program}

The stress paths of the five triaxial tests are presented in Figure 6 in terms of the mean net stress $\mathrm{p}\left(p=\sigma_{m}-u_{g}\right.$, with $\sigma_{m}$ the total mean stress $-\sigma_{m}=\frac{\sigma_{1}+2 \sigma_{3}}{3}-$ and $u_{g}$ the pore gas pressure), the capillary pressure $\mathrm{p}_{\mathrm{c}}\left(p_{c}=u_{g}-u_{w}\right.$, with $u_{w}$ the pore water pressure $)$ and the deviatoric stress $\mathrm{q}\left(q=\sigma_{1}-\sigma_{3}\right)$.

For each test, a sample was first water saturated (Skempton coefficient greater than 0.97) (point A in Figure 6). At the end of the saturation, the confining pressure and the pore water pressure were respectively equal to $860 \mathrm{kPa}$ and $850 \mathrm{kPa}$. The sample was then isotropically consolidated (point B in Figure 6) : the total isotopic pressure was increased from $860 \mathrm{kPa}$ to $1000 \mathrm{kPa}$ while the bulk water pressure was maintained constant. The consolidation of the sample was verified by monitoring the bulk water volume. At the end of consolidation, the mean effective stress was equal to $150 \mathrm{kPa}$.

The first shear test was carried out under saturated conditions. The isotropic consolidation was followed by a drained shear test (pore water pressure remains equal to $850 \mathrm{kPa}$ ). The shearing rate was slow enough in order to ensure the proper drained conditions. The stress path of the first shear test corresponds to B-B' path in Figure 6. This test is a reference test for following comparisons.

For the four other tests, some carbon dioxide $\mathrm{CO}_{2}$ was introduced in the sample (from point $\mathrm{B}$ to point $\mathrm{C}$ in Figure 6); the guest gas pressure was equal to $975 \mathrm{kPa}$. During this phase, the total mean stress $\sigma_{m}$ and the pore water pressure were constant while the pore gas pressure was increased from $850 \mathrm{kPa}$ to $975 \mathrm{kPa}$. In other words, the mean net stress decreased from $150 \mathrm{kPa}$ to $25 \mathrm{kPa}(=1000-975)$ and the capillary pressure increased from 0 to $125 \mathrm{kPa}(=975-$ 850). 
The second shear test was carried out under the stress conditions described previously $\left(p=25 \mathrm{kPa}\right.$ and $\mathrm{p}_{\mathrm{c}}=125 \mathrm{kPa}$ ). It was a drained test. The stress path of the second shear test corresponds to C-C' path in Figure 6.

For the third test, from point $\mathrm{C}$ conditions, the soil sample was unloaded under undrained conditions (from point $\mathrm{C}$ to point $\mathrm{D}$ in Figure 6) : the total mean stress was decreased by increments from $1000 \mathrm{kPa}$ to $350 \mathrm{kPa}$. Throughout the test, neither water nor gas were allowed to drain out of the sample. The pore water pressure was monitored during the unloading, while it was not possible to control the pore gas pressure. The evolution of the mean net stress $p$ and the capillary pressure $p_{c}$ were thus unknown. When the equilibrium was reached, the sample was sheared at constant water content. The third shear test corresponds to the stress path D-D' presented in Figure 6.

The behaviour of the unsaturated soil subjected to a drained decrease of the capillary pressure was tested during the fourth test (from point $\mathrm{C}$ to point $\mathrm{E}$ in Figure 6). The pore water pressure was increased from $850 \mathrm{kPa}$ to $905 \mathrm{kPa}$, while the total mean stress and the pore gas pressure were maintained constant. In other words the mean net stress remained equal to $25 \mathrm{kPa}$ and the capillary pressure was decreased from $125 \mathrm{kPa}$ to $70 \mathrm{kPa}$ (=975-905). When the equilibrium was reached, the sample was sheared at a constant capillary pressure. The fourth shear test corresponds to the stress path E-E' presented in Figure 6.

The test 5 was again an unloading in undrained conditions, at the capillary pressure of $70 \mathrm{kPa}$ (from point $\mathrm{E}$ to point $\mathrm{F}$ in Figure 6); the sample was then undrained sheared. This last shear test corresponds to the stress path F-F' presented in Figure 6. The five stress paths carried out within this study are summarized in Table 4. 


\subsection{Test results}

\subsubsection{Application of the gas pressure (from point B to point C in Figure 6)}

For the 4 tests $(2,3,4$ and 5), the introduction of gas at a pressure of $975 \mathrm{kPa}$ induced an capillary pressure increase from 0 to $125 \mathrm{kPa}$ and a decrease of the mean net stress from $150 \mathrm{kPa}$ to $25 \mathrm{kPa}$ (see Figure 6). The volumetric strains versus time during the phase of gas introduction are presented in Figure 7.

The volume change of the unsaturated soil samples during the capillary pressure increase can be divided into 3 parts.

First, an immediate increase of the total sample volume was observed (negative volumetric strains). This expansion is due to 2 factors: on one hand the gas pressure is higher than the pore water pressure, which started up the water drainage of the sample. On the other hand, the very low permeability of the porous stone prevents the drainage process. The first initial expansion was followed by a volume decrease that corresponds to 1) the gas diffusion into the sample and 2) the water drainage. Finally, we can observe a total volume increase. Figure 7 shows that the test 2 was stopped too early. From this phase, one can see that introduction of gas into this marine sediment induces a global volume increase of the samples.

\subsubsection{Decrease of the capillary pressure (from point $C$ to point E in Figure 6)}

In order to study the unsaturated soil behaviour during a capillary pressure decrease, the pore water pressure was increased from $850 \mathrm{kPa}$ to $905 \mathrm{kPa}$, while mean stress and pore gas pressure remained constant (path C-E in Figure 6). In other words, the capillary pressure was decreased to $70 \mathrm{kPa}$, and the mean net stress remained equal to $25 \mathrm{kPa}$. The volume change of the samples \# 4 and \# 5 was monitored during the tests. For the test 5 the evolution of the volumetric strains versus time is presented in Figure 8. It can be observed that the capillary pressure decrease induces a swelling of the sample. The decrease of the capillary pressure can indeed be seen as a decrease of soil inter-particles contact forces. 


\subsubsection{Mechanical undrained unloading (paths E-F and C-D in Figure 6).}

These tests evaluate the unsaturated soil behaviour submitted to undrained unloading at two different start capillary pressures (125 kPa for test 3 and $70 \mathrm{kPa}$ for test 5). This undrained unloading simulates the unloading (tidal cycles, erosion, natural slope instabilities, excavation) of a submarine slope.

\subsubsection{Results of the test 3}

The sample was initially submitted to a $1000 \mathrm{kPa}$ confining pressure, a pore water pressure of $850 \mathrm{kPa}$ and a pore gas pressure of $975 \mathrm{kPa}$. The confining pressure was reduced by increments. The duration of each stage and the corresponding stress conditions are given in Table 5. Because of the experimental device, it was not possible to measure the pore gas pressure evolution during this phase. For a saturated soil, the decrease of the confining pressure in undrained conditions induces the same decrease of pore water pressure. In any case, it is not possible for the decrease of pore water pressure to be higher than the confining pressure decrease. However for the first two unloading steps, the Skempton coefficient (variation of pore water pressure $\Delta \mathrm{u}_{\mathrm{w}}$ divided by variation of confining pressure $\Delta \sigma$ ) was greater than 1, which is probably related to the pore water dissipation generated by the previous loadings.

The last two unloading steps were probably long enough to reach the equilibrium at the end of the complete unloading. The Skempton coefficient of the complete unloading was equal to 0.87 (Table 5). From this result, we can conclude that mechanical unloading of unsaturated sediment at constant water content induces gas expansion, which generates an excess pore water pressure within the marine sediment.

\subsubsection{Results of the test 5}

For this test, the sample was initially submitted to the following stress conditions : a confining water pressure of $1000 \mathrm{kPa}$, a $905 \mathrm{kPa}$ pore water pressure and a pore gas pressure of 
$975 \mathrm{kPa}$. The duration of each step and the corresponding stress conditions are presented in Table 6.

For this test, unloading steps were longer than the test 3 . However it seems that again for the first two unloading steps, the equilibrium was not reached during the initial loading phase. The Skempton coefficient was indeed greater than 1. The evolution of pore water pressure as a function of confining pressure is presented in Figure 9.

Once equilibrium was reached (estimated at a confining pressure of $950 \mathrm{kPa}$ and a pore water pressure of $782 \mathrm{kPa}$ ), two types of evolution of the pore water pressure can be noticed (Figure 9) :

1) For a confining pressure between $950 \mathrm{kPa}$ and $700 \mathrm{kPa}$, the Skempton coefficient $\mathrm{B}$ (= $\left.\Delta \mathrm{u}_{\mathrm{w}} / \Delta \sigma\right)$ is relatively constant and equals to 0.65 .

2) For a confining pressure between 700 and $350 \mathrm{kPa}, \Delta \mathrm{u}_{\mathrm{w}} / \Delta \sigma$ is equal to 0.35 .

In Figure 10 the volumetric strains versus time for the unloading steps are presented with the confining pressure between $1000 \mathrm{kPa}$ and $600 \mathrm{kPa}$. It can be observed that for the first three steps (confining pressure decreased from $1000 \mathrm{kPa}$ to $900 \mathrm{kPa}$ ), the volumetric strains were positive (maximum volumetric strains equal $0.7 \%$ ). In other words the sample volume decreases. However large negative volumetric strains $(-3.5 \%)$ were observed during the decrease of the confining pressure from $900 \mathrm{kPa}$ to $600 \mathrm{kPa}$ (Figure 10).

During the two last unloading steps, confining pressure decreased from $600 \mathrm{kPa}$ to $350 \mathrm{kPa}$ and pore water pressure decreased from $582 \mathrm{kPa}$ to $494 \mathrm{kPa}$. The Skempton coefficient was thus equal to 0.35 . The consequence is a large expansion of the soil sample (around $4.5 \%$ ) as it can be seen in Figure 11.

This test shows an important feature of the unsaturated marine sediment behaviour during unloading at constant water content:

1) The decrease of the pore water pressure is lower than the decrease of the total 
confining pressure (Skempton coefficient lower than 1). Moreover the Skempton coefficient decreases with the total confining pressure.

2) The confining pressure decrease induces a gas expansion and consequently a global expansion of the marine sediment sample.

The experimental results from Figure 8 through Figure 10 show that unloading a natural submarine slope (sea level change, tidal cycles, erosion, natural slope instabilities, excavation) at low water depth is much more hazardous then unloading the same submarine slope at higher water depth.

\subsubsection{Shearing}

The stress conditions before shearing for the five tests are summarized in Table 7 . Figure 12 presents the results of the five triaxial tests in terms of deviatoric stress, volumetric strains and shear strains.

The shear tests allow the evaluation of the gas influence on the deviatoric soil properties. The deviatoric behaviour of the 5 samples of Figure 12 can be divided into two classes. For the tests 3, 4 and 5, the deviatoric behaviour is typical of an overconsolidated soil: on one hand the deviatoric curves show a peak value following by a softening of the marine sediment. On the other hand the volumetric strain curves show an expansion of the sediment samples. For the tests 3 and 5, the soil was mechanically unloaded generating a decrease of the mean effective stress, which can explain a mechanical overconsolidated behaviour of the soil. Before shearing in test 4 , the soil was submitted to a start capillary pressure of $125 \mathrm{kPa}$ and it was then decreased to $70 \mathrm{kPa}$. In this case the marine sediment can be considered apparently overconsolidated (see for instance Sultan et al. 2001).

For tests 1 and 2, the soil was normally consolidated for both mechanical and hydraulic loadings. It behaves as a normally consolidated soil: a continuous hardening of the material (Figure 12-a) and a global compression of the sample during the shear test (Figure 12-b). 
From the shearing tests of Figure 12-a, we can study the effect of the capillary pressure on the shear resistance of the soil. The comparison of test 1 with test 2 shows that under drained conditions, the shear resistance increases with capillary pressure (or gas content). Indeed, for an increase of $125 \mathrm{kPa}$ in capillary pressure, the soil shear resistance increases by about $25 \mathrm{kPa}$ (at 10\% shear strain). The conclusion is that under drained conditions, an unsaturated marine soil is more resistant under shearing than a saturated soil.

Comparison of test 4 with test 5 shows a decrease of around $30 \mathrm{kPa}$ of the shear resistance generated by the mechanical unloading. By comparing test 2 to test 3 a $70 \mathrm{kPa}$ decrease of the shear resistance was observed. These results show that the mechanical unloading in undrained conditions generates a decrease of the marine sediment resistance. Moreover the decrease of the shear resistance depends on the initial gas content: a decrease of $30 \mathrm{kPa}$ of the shear resistance at a capillary pressure of $70 \mathrm{kPa}$ and a decrease of $70 \mathrm{kPa}$ of the shear resistance at a capillary pressure of $125 \mathrm{kPa}$.

The conclusion of these deviatoric tests is particularly interesting in the case of shallow submarine slopes. Indeed, a sudden decrease of the total pressure (tidal cycles, erosion, excavation, small initial sediment failures) applied on a submarine unsaturated sediment slope, will generate a decrease of the sediment shear resistance below the seafloor. The decrease of the shear resistance could then initiate other important retrogressive submarine slope failures. 


\section{Hydro-mechanical behaviour of unsaturated soil : theoretical approach}

An elastoplastic critical state framework for unsaturated soil was developed by Alonso et al. in 1990. The experimental results were quite in accordance with the model predictions for drying and loading paths. However the model was unable to reproduce the large swelling strains exhibited by certain sediments during unloading. These sediments are called expansive because of their swelling behaviour. Therefore the previous model has been modified for this type of sediment (Gens and Alonso 1992 and Alonso, Gens and Gehling 1994). The new model of Alonso, Gens and Gehling (1994) is able to predict volumetric strains and shear strains for any stress path with drained conditions. However it cannot be used to predict the behaviour during undrained paths because it doesn't provide any information on the variation of saturation degree (Wheeler 1996). Therefore, and in order to take into account this special behaviour of unsaturated soil during unloading, additional equations relating the change of degree of saturation have been included in the model of Alonso and co-workers.

Variables used for the description of the model are the stress state variables defined at section

$4: \mathrm{p}$ the mean net stress $\left(p=\sigma_{m}-u_{g}\right.$, with $\sigma_{m}$ the total mean stress $-\sigma_{m}=\frac{\sigma_{1}+2 \sigma_{3}}{3}-$ and $u_{g}$ the pore gas pressure), the capillary pressure $\mathrm{p}_{\mathrm{c}}\left(p_{c}=u_{g}-u_{w}\right.$, with $u_{w}$ the pore water pressure) and the deviatoric stress $\mathrm{q}\left(q=\sigma_{1}-\sigma_{3}\right)$.

\subsection{Constitutive model}

\subsubsection{Microstructural and macrostructural behaviours}

The model of Alonso et al (1994) considered two distinct levels of unsaturated soil: the microstructural level, which corresponds to the active clay minerals, and the macrostructural level, for major structure of the soil. 
The microstructural level is considered saturated and the effective stress concept may be used. The microstructural strains are considered volumetric and elastic, and independent of the macrostructure; these strains depend only on the increment $d\left(p+p_{c}\right)$. Therefore, the straight line $p+p_{c}=$ constant is a neutral line, where no microstructural deformations occur. This line is called Neutral Line (NL, see Figure 13), and separates the zone of microstructural swelling and the zone of microstructural collapse in the $p-p_{c}$ plane.

Two additional yield loci are introduced in the model : Suction Increase (SI) line and Suction Decrease (SD) line (see Figure 13). They are parallel to the Neutral Line NL and define the elastic area, in which strains are only reversible. Irreversible strains are generated when the stress state reaches one of these two lines.

The yield locus related at the macrostructural level is the LC surface (see Figure 13). When the stress path crosses this yield curve in the $p-p_{c}$ plane, irreversible macrostructural volumetric strains occur. This may be due to a decrease of capillary pressure (which induces collapse strains), or an increase of loading (which induces loading strains). To the left of this curve, in the elastic area, a change of $p$ or $p_{c}$ induces reversible strains.

A coupling exists between these three yield surfaces SD, SI and LC. Lets consider a soil sample, that is affected by a decrease of capillary pressure (from point A to point B in Figure 14-a). This decrease of $\mathrm{p}_{\mathrm{c}}$ induces the development of microstructural swelling $\left(\mathrm{SD}_{\mathrm{i}}\right.$ tends towards $\mathrm{SD}_{\mathrm{f}}$ ). Thus, the soil skeleton (macrostructure) will be affected by this swelling, and the macrostructural void ratio increases. This plastic volume change leads in turn to a movement of the yield surface $\mathrm{LC}$ to the left $\left(\mathrm{LC}_{\mathrm{i}}\right.$ tends towards $\left.\mathrm{LC}_{\mathrm{f}}\right)$. The microstructural level is affected by the swelling, and yield curve $\mathrm{SI}$ moves too $\left(\mathrm{SI}_{\mathrm{i}}\right.$ tends towards $\left.\mathrm{SI}_{\mathrm{f}}\right)$. Figure 14-b presents the coupling due to an increase of the capillary pressure $p_{c}$. These coupling are expressed by the hardening laws. 
For triaxial stress state, the deviatoric stress variables $q$ is used. The developed model is based on the modified Cam Clay model. Thus, in the p-q plane, the yield curve for a sample at constant capillary pressure $\mathrm{p}_{\mathrm{c}}$ is described by an ellipse (see Figure 15). Yield lines SI and SD extend into the region $\mathrm{q}>0$ by means of planes parallel to the $\mathrm{q}$ axis (see Figure 15).

\subsubsection{Mathematical formulation}

\subsubsection{Elastic behaviour}

For stress paths inside the elastic area, Alonso et al.(1990) suggested the following equation for volumetric elastic strains:

$$
d \varepsilon_{v M}^{e}=\frac{\kappa}{v} \frac{d p}{p}+\frac{\kappa_{s}}{v} \frac{d p_{c}}{p_{c}+p_{a t}}
$$

where $v$ is the specific volume, $\kappa$ and $\kappa_{s}$ are respectively the elastic stiffness parameters for changes in $\mathrm{p}$ and $\mathrm{p}_{\mathrm{c}}$, and $p_{a t}$ is atmospheric pressure.

For triaxial stress states, a change in deviatoric stress generates shear elastic strains given by :

$$
d \varepsilon_{S}^{e}=\frac{d q}{3 G}
$$

The microstructural volumetric strain $d \varepsilon_{m}^{e}$ associated with changes in $\left(p+p_{c}\right)$ is expressed by :

$$
d \varepsilon_{v m}^{e}=\beta_{m} \exp \left(-\alpha_{m}\left(p+p_{c}\right)\right) d\left(p+p_{c}\right)
$$

where $\beta_{m}$ and $\alpha_{m}$ are microstructural parameters.

\subsubsection{Yield curves}

The preconsolidation pressure $p_{0}$, for the considered capillary pressure $p_{c}$, defines the position of the LC yield surface in the $p-p_{c}$ plane; it is expressed through the following 
relation :

$$
\frac{p_{0}}{p_{r}}=\left(\frac{p_{c 0}}{p_{r}}\right)^{\lambda(0)-\kappa}
$$

where $p_{c 0}$ is the preconsolidation stress for saturated conditions, $p_{r}$ is a reference stress, $\lambda(0)$ is the slope of the virgin saturated consolidation line and $\lambda\left(p_{c}\right)$ is a stiffness parameter given by :

$$
\lambda\left(p_{c}\right)=\lambda(0)\left[(1-r) \exp \left(-\beta p_{c}\right)+r\right]
$$

where $r$ is a parameter defining the maximum soil stiffness and $\beta$ is a parameter controlling the rate of increase of soil stiffness with capillary pressure.

$\lambda\left(p_{c}\right)$ corresponds to the slope of the virgin consolidation line at capillary pressure $\mathrm{p}_{\mathrm{c}}$.

In the p-q plane, the yield curve is an ellipse, which extends due to capillary pressure increase; its equation is:

$$
q^{2}-M^{2}\left(p+k p_{c}\right)\left(p_{0}-p\right)=0
$$

where $M$ is the slope of critical state lines and $k$ is a parameter describing the cohesion increase with capillary pressure.

In the model of Cam Clay, the failure state is defined by a critical state line in the p-q plane; this line goes through origin with the slope $M$ (see Figure 16). The effect of capillary pressure on the sample is to increase the cohesion; this feature can be represented in terms of the critical state line by maintaining the slope $M$ and by intersecting the $\mathrm{p}$ axis at the point at which $p=-p_{S}=-k p_{c} .($ Figure 16). 


\subsubsection{Flow rules}

Microstructural strains $d \varepsilon^{e} m$ lead to softening/hardening of the macrostructure by the development of irreversible strains $d \varepsilon_{v M}^{p}$ when yield curves are reached.

When yield curve SI or SD is reached, a change in $p$ or $p_{c}$ leads to the following plastic strains, respectively $d \varepsilon_{v M I}^{p}, d \varepsilon_{v M D}^{p}$ :

$$
\begin{aligned}
& d \varepsilon_{v M I}^{p}=\beta_{m} \exp \left(-\alpha_{m}\left(p+p_{c}\right)\right) d\left(p+p_{c}\right) t_{I}\left(1-\frac{p}{p_{0}}\right)^{n} I \\
& d \varepsilon_{v M D}^{p}=\beta_{m} \exp \left(-\alpha_{m}\left(p+p_{c}\right)\right) d\left(p+p_{c}\right) t_{D}\left(1-\frac{p}{p_{0}}\right)^{n} D
\end{aligned}
$$

where $p$ is the current mean net stress, $p_{0}$ is the preconsolidation stress for the considered capillary pressure and $t_{I}, t_{D}, n_{I}$ and $n_{D}$ are model parameters.

Once the LC surface is reached an increase of the total mean net stress or/and the capillary pressure induces plastic irreversible strains $d \varepsilon_{v}^{p}$. In case of triaxial stress, the plastic shear strain increment $d \varepsilon_{q}^{p}$ depends on the plastic volumetric strain increment $d \varepsilon_{v}^{p}$ with the relation:

$$
\frac{d \varepsilon_{q}^{p}}{d \varepsilon_{v}^{p}}=\frac{2 \alpha q}{M^{2}\left(2 p+k p_{c}-p_{0}\right)}
$$

The constant $\alpha$ is equal to :

$$
\alpha=\frac{M(M-9)(M-3)}{9(6-M)}\left\{\frac{1}{1-\kappa / \lambda(0)}\right\}
$$

\subsubsection{Hardening laws}

Positions of SD and SI are defined with parameters $s_{h}$ and $s_{0}$ respectively (see Figure 15).

SI and SD hardening is governed by the total volumetric plastic strain due to activation of SI 
and SD $\left(d \varepsilon_{v M I}^{p}+d \varepsilon_{v M D}^{p}\right)$. The hardening law for the yield locus SI is expressed by:

$$
d s_{0}=\frac{d \varepsilon_{v M I}^{p}+d \varepsilon_{v M D}^{p}}{\beta_{m} e^{-\alpha_{m} s_{0}} t_{I}\left(1-p / p_{0}\right)^{n} I}
$$

Similary, for the yield locus SD:

$$
d s_{h}=\frac{d \varepsilon_{v M I}^{p}+d \varepsilon_{v M D}^{p}}{\beta_{m} e^{-\alpha_{m}{ }^{s} h_{t}}{ }_{D}\left(1-p / p_{0}\right)^{n} D}
$$

Once the LC surface is reached, the plastic strains generate an increase of the preconsolidation pressure previously reached by the soil. In the model, it is postulated that microstructure has influence on macrostructure; so the hardening law of LC is given by Equation 14 where $p_{c 0}$ depends on the microstructural plastic strains $d \varepsilon_{v M}^{p}$ :

$$
\frac{d p_{c 0}}{p_{c 0}}=\frac{v}{\lambda(0)-\kappa}\left(d \varepsilon_{v}^{p}+d \varepsilon_{v M I}^{p}+d \varepsilon_{v M D}^{p}\right)
$$

\subsection{Hydro-mechanical behaviour of unsaturated soil under constant water content}

The model previously described can not predict tests at constant water content because there are no relations between water content (or water degree of saturation $\mathrm{Sr}_{\mathrm{w}}$ ) and the three stress state variables $\left(\mathrm{p}, \mathrm{q}, \mathrm{p}_{\mathrm{c}}\right)$.

Alonso et al (1990) proposed a relationship where the degree of saturation $\mathrm{Sr}_{\mathrm{w}}$ depends markedly on capillary pressure $\mathrm{p}_{\mathrm{c}}$ whereas the influence of applied stress is small :

$$
S r_{w}=1-L \tanh \left(N p_{c}\right)
$$

where $\mathrm{L}$ and $\mathrm{N}$ are constants. This relation can be used for water degree of saturation greater than 0.4 . 
An other relationship, between $\mathrm{Sr}_{\mathrm{w}}$ and $\mathrm{p}_{\mathrm{c}}$, has been proposed by Van Genuchten (1980) for the whole range of degree of saturation:

$$
p_{c}=u_{g}-u_{w}=\frac{\left[\left(\frac{S r_{w}-\theta_{r}}{\theta_{s}-\theta_{r}}\right)^{\frac{-1}{m}}-1\right]^{\frac{1}{n}}}{\alpha}
$$

This relation needs the knowledge of five shape parameters: $\theta_{r}, \theta_{s}, \alpha, m$ and $n$ (Figure 17). In this work, in order to consider the whole range of degree of saturation, we use the relation proposed by Van Genuchten.

\subsubsection{Compressibility and solubility of the gas}

Experimental results have shown that the decrease of pore water pressure during unsaturated soils undrained unloading is smaller than the decrease of total stress. This particular behaviour is due to the gas compressibility and solubility.

The compressibility of a free gas is described by Boyle's law which states that the gas volume varies inversely with gas pressure at a constant temperature. The gas solubility is described by Henry's law which states that the mass of gas dissolved in the water is directly proportional to the absolute gas pressure above the solution, at a constant temperature.

\subsubsection{Model formulation}

By differentiating Equation 16 with respect to time, we obtain: 


$$
d u_{g}-d u_{w}=\frac{-\left[\left(\frac{S r_{w}-\theta_{r}}{\theta_{s}-\theta_{r}}\right)^{-\frac{1}{m}}-1\right]^{\frac{1}{n}}}{n} \frac{\left(\frac{S r_{w}-\theta_{r}}{\theta_{s}-\theta_{r}}\right)^{-\frac{1}{m}}}{\left[m\left(S r_{w}-\theta_{r}\right)\left[\left(\frac{S r_{w}-\theta_{r}}{\theta_{s}-\theta_{r}}\right)^{-\frac{1}{m}}-1\right] \alpha\right]} d S r_{w}
$$

where $d u_{g}$ and $d u_{w}$ are respectively gas and water pore pressure increments, and $d S r_{w}$ is the degree of saturation increment.

In this equation, the effect of the changes in porosity (and thus in $m, n, \alpha, \theta_{s}$ and $\theta_{r}$ ) is neglected with regard to the evolution of $S r_{w}$.

The volumetric strain rate $d \varepsilon=-d V_{v} / V$ (where $V_{v}$ is voids volume and $V$ total volume) can be expressed in terms of $d \varepsilon^{g}=-d V_{g} / V$ and $d \varepsilon^{w}=-d V_{w} / V$ (where $d V_{g}$ and $d V_{w}$ are respectively gas and water volume change), then :

$$
d \varepsilon=\frac{V_{g}}{V} d \varepsilon^{g}+\frac{V_{w}}{V} d \varepsilon^{w}
$$

Considering water to be incompressible, we have $d V_{w}=0$. Thus, since $S r_{w}=V_{w} / V_{v}$, and using Equation 18, we find:

$$
d S r_{w}=S r_{w}\left(1-S r_{w}\right) d \varepsilon^{g}
$$

Equation 18 can be supplemented by the constitutive relation between variation of gas volume and variation of gas pore pressure:

$$
d u_{g}=K_{a} d \varepsilon^{g}
$$

where $K_{a}$ is the bulk modulus of air. Using Boyle's and Henry's laws to the total volume of 
gas (free gas $V_{g}$ and dissolved gas $V_{d}$ ), the modulus $K_{a}$ is developed, and we obtain the following relation:

$$
d u_{g}=\left(u_{g}+p_{a t}\right)\left(\frac{1-S r_{w}}{1-S r_{w}+H S r_{w}}\right) d \varepsilon^{g}
$$

where $H$ is the coefficient of solubility. Although the value of $H$ is affected by the gas pressure ( $H$ increases with increasing gas pressure), it is taken constant in the model.

The change of gas and water pore pressures due to change of total stress at constant water content cannot be directly determined with the previous equations. For each increment of total stress, the change of gas pore pressure is first arbitrarily chosen; the change of gas volume is calculated with Equation 21, as well as changes of degree of saturation and water pore pressure (with equations 17 and 19). Therefore, the new stress paths are completely determined and the total volume change of the soil is calculated using the Alonso et al. (1990) model. The correct gas pressure value is then calculated by iteration in order to obtain a soil volume change from the Alonso et al. model equal to the gas volume change obtained from equation 21 .

\subsection{Model parameters}

The parameters used in the model previously described are: parameters of initial state $\left(p_{c 0}, s_{0}, s_{h}, e_{0}, S_{r 0}\right)$; parameters associated with LC yield curve $\left(\lambda(0), \kappa, \beta, p_{c}, r\right)$; parameters associated with capillary pressure changes $\left(\kappa_{s}, \alpha_{m}, \beta_{m}, t_{I}, n_{I}, t_{D}, n_{D}\right)$; and parameters associated with changes in shear stress and strength $(G, M, k)$.

The determination of the model parameters requires capillary pressure-controlled tests. Isotropic drained compression tests at several constant capillary pressure values provide data to determine parameters associated with LC yield curve $\left(\lambda(0), \kappa, \beta, p_{c}, r\right)$ and the 
preconsolidation stress for saturated conditions $p_{c 0}$. In the same way, drying-wetting cycles at constant mean net stress values allow to obtain $\kappa_{s}, s_{0}$ and $s_{h}$; with the same tests $\alpha_{m}, \beta_{m}, t_{I}, n_{I}, t_{D}, n_{D}$ may be approximated with percentage of irreversible strains. Parameters $G, M, k$ are obtained with drained shear strength tests at different capillary pressures. The five parameters $\left(\theta_{r}, \theta_{s}, \alpha, m, n\right)$ of the equation of Van Genuchten (Equation 16) are determined from the mercury porosimeter curve.

\subsection{Model predictions}

Due to the lack of experimental data for marine unsaturated sediment, allowing the determination of the relevant parameters, and in order to validate the implementation of the proposed model, we consider a theoretical case where the unsaturated sediment is taken at $40 \mathrm{~m}$ below the seafloor, with a total sediment unit weight of $16 \mathrm{kN} / \mathrm{m}^{3}$. The gas is the carbon dioxide. The parameters used for the theoretical simulations are indicated in Table 8 . The Henry's constant is taken to be equal to 0.00027 ; the drainage curve parameters $\left(\theta_{r}, \theta_{s}, \alpha, m, n\right)$ are taken respectively as $0.083,1.09,0.0167 \mathrm{kPa}^{-1}, 99 \%$ and $5 \%$.

\subsubsection{Volumetric behaviour of unsaturated soil: unloading under undrained conditions}

In the following, we simulate the response of the marine soil (with the parameters described in Table 8) for different stress paths under undrained conditions using the model previously described.

For unloading, and as a case study, we consider the response of the soil under 3 undrained unloading stages which correspond respectively to the loss of $2 \mathrm{~m}$ (point 1 - Figure 18), $6 \mathrm{~m}$ (point 2 - Figure 18) and $10 \mathrm{~m}$ (point 3 - Figure 18) of the soil layer thickness (tidal cycles, erosion, excavation or slope instability) above the considered marine sediment sample.

Figure 18-a presents the gas pressure evolution during the undrained unloading generated by 
the soil layer thickness decreases above the considered marine sediment. This curve shows a non-linear decrease of gas pressure with the mean stress decrease. Above $550 \mathrm{kPa}$, the unloading stress path is in the elastic area, and a small gas pressure decrease is observed (only $2 \mathrm{kPa}$ ) for a decrease of $100 \mathrm{kPa}$ of the mean stress. When the stress path reaches the SD yield surface (point 2), the volumetric strain of the soil (which is equal to the change of volume of gas) becomes more important, and so the gas pressure decreases more quickly $\left(\Delta \mathrm{u}_{\mathrm{g}} / \Delta \sigma=0.1\right)$. In Figure 18-b the capillary pressure as a function of the mean stress during the unloading process is presented. One can observe an increase of the capillary pressure generated by a decrease of the total stress. The very small increase calculated here is a consequence of the used parameters.

\subsubsection{Deviatoric behaviour of unsaturated soil : unloading under undrained conditions}

In terms of deviatoric behaviour, the undrained unloading has no consequence for saturated soil. However, for unsaturated marine sediment the decrease of the mean net stress induces a decrease of the shear strength. In Figure 19 we present the shear strength as a function of shear strains for the three unloaded cases in Figure 18. Figure 19 shows clearly a decrease of the maximum shear strength with the increase of the unloading level. For unloading corresponding to $10 \mathrm{~m}$ of the soil thickness above the considered marine sediment sample, one can observe a drop of around $60 \%$ of the maximum shear strength with respect to the intact soil layer. From Figure 19, one can conclude that the shear strength of unsaturated marine sediment is strongly influenced by the total stress levels under undrained conditions. Figure 19 shows clearly that unsaturated marine sediment behaviour could be very hazardous when it is unloaded in undrained conditions. The simulation results show that unloading a natural submarine slope (tidal cycles, erosion, natural slope instabilities, excavation) at low water depth is much more hazardous then unloading the same submarine slope at higher water depth. 


\section{Conclusions}

In our project, a new triaxial cell was developed in order to control separately the different stress state variables, controlling the marine unsaturated sediment behaviour. Three null tests were carried out to identify the stress state variables. A series of experimental tests were conducted to identify the main behaviour of a synthetic unsaturated marine sediment. Special attention was devoted to the experimental behaviour of the unsaturated marine sediment under undrained conditions, which simulates the sudden unloading (tidal cycles, erosion, natural slope instabilities, excavation) of a submarine slope. The experimental results have shown that a decrease of the capillary pressure under undrained conditions (so an increase of the degree of saturation) generates a swelling of the soil.

The increase of the capillary pressure (decrease of the degree of saturation) in drained conditions increases the shear resistance of the marine sediment. However, the mechanical undrained unloading generates on one hand a decrease of the mean effective stress and on the other hand an important decrease of the undrained shear sediment resistance. Thus, unloading in undrained conditions an unsaturated marine sediment could be very hazardous.

The development of a new mathematical formulation based on previous constitutive models (Alonso et al. 1990 and Gens et al. 1992), allowed the prediction of the main features of unsaturated marine sediment behaviour.

Simulation results in terms of volumetric behaviour show that during undrained unloading, the Skempton coefficient decreases with the total load. For the deviatoric behaviour, the undrained unloading induces a decrease of the undrained shear strength, which depends on the total stress levels. Qualitative comparison between experimental results and model predictions shows the capacity of the proposed model to reproduce reasonably the essential features of the hydro-mechanical behaviour of unsaturated marine soil. Experimental and simulations results show that unloading (tidal cycles, erosion, natural slope instabilities, 
excavation) a submarine unsaturated sediment slope at low water depth is much more hazardous then unloading the same submarine slope at higher water depth. 


\section{REFERENCES}

Alonso E.E., Gens A., Josa A., 1990. A constitutive model for partially saturated soils. Géotechnique 40(3), 405-430.

Alonso E.E., Gens A., Gehling W.Y, 1994. Elastoplastic model for unsaturated expansive soils. In: Smith (ed.), Numerical Methods in Geotechnical Engineering.

Alonso E.E., Vaunat J., Gens A., 1999. Modelling the mechanical behaviour of expansive clay. Engineering Geology 54, 173-183.

Biot M.A., 1941. General theory of three-dimensional consolidation. Journal of Applied Physics 12, 155-164.

Bishop A.W., 1959. The principle of effective stress. Tecknisk Ukeblad 106(39), 859-863.

Coleman J.D., 1962. Stress strain relations for partly saturated soil. Géotechnique 12(4), 348350 .

Cui, Y.J., Delage, P. and Sultan, N., 1995. An Elastoplastic Model for Compacted Soils, Unsaturated Soils/ Proc. 1st Int. Conf. on Unsaturated Soils (UNSAT 95), Alonso, E.E. and Delage, P. (Eds), Rotterdam,pp. 703-709.

Cui, Y.J. and Delage, P., 1996. Yielding and plastic behaviour of an unsaturated compacted silt. Géotechnique 46: 291-311.

Fredlund D.G. \& Morgenstern N.R., 1977. Stress state variables for unsaturated soils. ASCE 103(GT5), 447-466.

Gens A., Alonso E.E., 1992. A framework for the behaviour of unsaturated expansive clays. Canadian Geotechnical Journal 29, 1013-1032.

Jennings J.E.B. \& Burland J.B., 1962. Limitations to the use of effective stresses in partly saturated soils. Géotechnique 12(2), 125-144.

Matyas, E.L. and Radhakrishna, H.S. 1968. Volume change characteristics of partially saturated soil. Géotechnique 18, 432-448.

Meunier, J., Sultan, N., Jegou, P and Harmegnies F. 2004. First tests of Penfeld: a new seabed penetrometer. Proceedings of The Fourteenth International Offshore and Polar Engineering Conference, Toulon, France.

Pietruszczak, S. and Pande, G.N., 1996. Constitutive relations for partially saturated soils containing gas inclusions. Journal of Geotechnical Engineering 122 (1), 50-59.

Sheng, D., Sloan S.W. and Gens A. 2004. A constitutive model for unsaturated soils: thermomechanical and computational aspects. Computational Mechanics, 33. 
Sultan N., Cochonat P., Dennielou B., Bourillet J.F., Savoye B. and Colliat J.L. 2000. Surconsolidation apparente et pression osmotique dans un sédiment marin, Comptes Rendus de l'Académie des Sciences - Series IIA - Earth and Planetary Science, 331(5),379-386.

Sultan N., Cochonat P., Foucher J.P. and Mienert J. this volume. Effect of gas hydrates melting on seafloor slope instability.

Terzaghi, C., 1927. Principles of Final Soil Classification. Public Roads 8(3), 41-53.

Van Genuchten, M. Th., 1980. A closed-form equation for predicting the hydraulic conductivity of unsaturated soils. Soil Science Society Am. Journal 44, 892-898.

Wheeler S.J., 1988. A conceptual model for soils containing large gas bubbles. Géotechnique 38, 389-397.

Wheeler S.J., 1996. Inclusion of specific water volume within an elasto-plastic model for unsaturated soil. Canadian Geotechnical Journal 33, 42-57.

Wheeler S.J., Sharma R.S. and Buisson MSR, 2003. Coupling of hydraulic hysteresis and stress-strain behaviour in unsaturated soils. Geotechnique 53(1), 41-54. 


\begin{tabular}{cccc}
\hline Void ratio & Permeability & Consolidation coefficient & Loading \\
$\mathbf{e}(-)$ & $\mathbf{k}\left(\mathbf{m . s}^{-\mathbf{1}}\right)$ & $\mathbf{C v}\left(\mathbf{m}^{\mathbf{2}} / \mathbf{s}\right)$ & $\mathbf{( k P a )}$ \\
\hline 5.72 & $2.495 * 10^{-9}$ & $2.66 * 10^{-8}$ & 25 \\
5.26 & $1.457 * 10^{-9}$ & $1.26^{*} 10^{-8}$ & 51 \\
4.40 & $6.29 * 10^{-10}$ & $9.429 * 10^{-9}$ & 102 \\
3.76 & $3.22 * 10^{-10}$ & $9.5 * 10^{-9}$ & 204 \\
\hline
\end{tabular}

Table 2 : Sample properties 


\begin{tabular}{ccccccc}
\hline \multirow{2}{*}{ Test } & Pressure & \multicolumn{3}{c}{ Consolidation pressure } & Maximum & Maximum \\
\cline { 3 - 5 } Number & increment & Total & Gas & Water & sample volume & water volume \\
& $(\mathrm{kPa})$ & $(\mathrm{kPa})$ & $(\mathrm{kPa})$ & $(\mathrm{kPa})$ & change $(\%)$ & change $(\%)$ \\
\hline $\mathrm{NT} 1$ & +45 & 545 & 325 & 245 & -0.011 & +0.014 \\
\hline $\mathrm{NT} 2$ & +38 & 583 & 363 & 283 & -0.028 & +0.048 \\
\hline $\mathrm{N}$ & -183 & 453 & 210 & 153 & -0.032 & +0.026 \\
\hline
\end{tabular}

Table 3 : Summary of the Null Tests. 


\begin{tabular}{|c|c|c|c|c|}
\hline & \multirow{2}{*}{ Stress path } & \multicolumn{3}{|c|}{ Shearing Conditions } \\
\hline & & & $\mathrm{p}$ & $\mathrm{p}_{\mathrm{c}}$ \\
\hline Test 1 & Saturation - consolidation - shearing & drained & $150 \mathrm{kPa}$ & $0 \mathrm{kPa}$ \\
\hline Test 2 & $\begin{array}{c}\text { Saturation - consolidation - gas introduction - } \\
\text { shearing }\end{array}$ & drained & $25 \mathrm{kPa}$ & $125 \mathrm{kPa}$ \\
\hline Test 3 & $\begin{array}{c}\text { Saturation - consolidation - gas introduction - } \\
\text { undrained unloading - shearing }\end{array}$ & undrained & unknown & unknown \\
\hline Test 4 & $\begin{array}{l}\text { Saturation - consolidation - gas introduction - } \\
\text { capillary pressure decreasing - shearing }\end{array}$ & drained & $25 \mathrm{kPa}$ & $70 \mathrm{kPa}$ \\
\hline Test 5 & $\begin{array}{l}\text { Saturation - consolidation - gas introduction - } \\
\text { capillary pressure decreasing - } \\
\text { undrained unloading - shearing }\end{array}$ & undrained & unknown & Unknown \\
\hline
\end{tabular}

Table 4 : Characteristics of the experimental tests performed 


\begin{tabular}{ccccc}
\hline $\begin{array}{c}\text { Number of } \\
\text { step }\end{array}$ & $\begin{array}{c}\text { Applied confining } \\
\text { pressure }(\mathrm{kPa})\end{array}$ & $\begin{array}{c}\text { Measured pore } \\
\text { water pressure } \\
(\mathrm{kPa})\end{array}$ & $\begin{array}{c}\text { Skempton } \\
\text { Coefficient }\end{array}$ & $\begin{array}{c}\text { Duration of the } \\
\text { step (minute) }\end{array}$ \\
\hline Initial state & 1000 & 850 & $1.13^{*}$ & 306 \\
\hline 1 & 900 & 737 & $1.11^{*}$ & 1110 \\
\hline 2 & 700 & 516 & 0.71 & 7183 \\
\hline 4 & 500 & 374 & 0.607 & \\
\hline Total & 350 & 283 & $\mathbf{0 . 8 7}$ & \\
\hline
\end{tabular}

* equilibrium was not reached during the initial loading phase

Table 5: Phase of unloading at constant water content for test 3 (from $C$ to $D$ in Figure 6). 


\begin{tabular}{|c|c|c|c|c|}
\hline $\begin{array}{c}\text { Number of } \\
\text { step }\end{array}$ & $\begin{array}{c}\text { Confining } \\
\text { pressure }(\mathrm{kPa})\end{array}$ & $\begin{array}{c}\text { Pore water } \\
\text { pressure }(\mathrm{kPa})\end{array}$ & $\begin{array}{l}\text { Skempton } \\
\text { coefficient }\end{array}$ & $\begin{array}{l}\text { Duration of the } \\
\text { step (minute) }\end{array}$ \\
\hline Initial state & 1000 & 890 & & 40 \\
\hline 1 & 970 & 814 & $2.53 *$ & 1509 \\
\hline 2 & 950 & 782 & $1.60 *$ & 1649 \\
\hline 3 & 900 & 747 & 0.70 & 1460 \\
\hline 4 & 800 & 695 & 0.52 & 1290 \\
\hline 5 & 700 & 621 & 0.74 & 2674 \\
\hline 6 & 600 & 582 & 0.39 & 1895 \\
\hline 7 & 500 & 553 & 0.29 & 1400 \\
\hline 8 & 350 & 494 & 0.39 & 6830 \\
\hline Total & & & 0.61 & \\
\hline
\end{tabular}

Table 6 : Step of unloading at constant water content for test 5 (from $E$ to $F$ in Figure 6 ). 


\begin{tabular}{ccccccc}
\hline Test & Confining & Pore water & Pore gas & Mean net & Capillary & Drained/ \\
Number & pressure & pressure & pressure & stress & pressure & undrained \\
& $(\mathrm{kPa})$ & $(\mathrm{kPa})$ & $(\mathrm{kPa})$ & $(\mathrm{kPa})$ & $(\mathrm{kPa})$ & \\
\hline 1 & 1000 & 850 & 850 & 150 & 0 & Drained \\
\hline 2 & 1000 & 850 & 975 & 25 & 125 & Drained \\
\hline 3 & 350 & 283 & unknown & unknown & unknown & Undrained \\
\hline 4 & 1000 & 905 & 975 & 25 & 70 & Drained \\
\hline 5 & 350 & 494 & unknown & unknown & unknown & Undrained \\
\hline
\end{tabular}

Table 7 : Stress conditions before shearing for the five tests. 


\section{Parameters associated with}

LC yield surface Capillary pressure changes Shear

\begin{tabular}{|c|c|c|c|c|c|c|c|c|c|c|c|c|}
\hline$\lambda(0)$ & $\mathrm{K}$ & $\beta$ & $\mathrm{p}_{\mathrm{c}}$ & $\mathrm{R}$ & $\kappa_{\mathrm{s}}$ & $\alpha_{\mathrm{m}}$ & $\beta_{\mathrm{m}}$ & $\mathrm{n}$ & $\mathrm{t}$ & $\mathrm{G}$ & $\mathrm{M}$ & $\mathrm{k}$ \\
\hline & & $\mathrm{kPa}^{-1}$ & $\mathrm{kPa}$ & & & $\mathrm{kPa}$ & $\mathrm{kPa}^{-1}$ & & & $\mathrm{kPa}$ & & \\
\hline 0.22 & 0.022 & $1 * 10^{-4}$ & 5 & 0.55 & $9 * 10^{-4}$ & $6^{*} 10^{-5}$ & $1.4 * 10^{-5}$ & 0.01 & 10 & 5000 & 1.4 & 0.8 \\
\hline
\end{tabular}

Table 8 : Model parameters 


\section{LIST OF FIGURES}

Figure 1: a) In-situ measurement of the $P$ wave velocity as a function of depth $b$ ) gas degree of saturation $(\mathrm{Sg})$ calculated from the $\mathrm{P}$ wave velocity profile using the effective medium theory (Helgerud et al. 1999).

Figure 2: Triaxial cell for unsaturated soil

Figure 3: Result from NT1 Test

Figure 4: Result from NT2 Test

Figure 5: Result from NT3 Test

Figure 6: Stress paths for the five experimental tests

Figure 7. Volumetric strains - time diagram during application of the gas pressure (path B-C in Figure 6)

Figure 8: Volumetric strains during capillary pressure decreasing for test 5 (path C-E in Figure 6)

Figure 9: Evolution of pore water pressure as a function of the confining pressure during unloading at constant water content (test 5 , from $\mathrm{E}$ to $\mathrm{F}$ in Figure 6)

Figure 10: Volumetric strains and confining pressure versus time for different unloading steps at constant water content

Figure 11: Volumetric strains and confining pressure versus time generated by a decrease of the confining pressure from $600 \mathrm{kPa}$ to $350 \mathrm{kPa}$ at constant water content

Figure 12: a) Deviatoric stress - shear strains diagram b) Volumetric strains - shear strains diagram

Figure 13: Yield loci in $\mathrm{p}-\mathrm{p}_{\mathrm{c}}$ plane

Figure 14: Coupling between microstructural and macrostructural yield curves a) With a decrease of capillary pressure - b) With an increase of capillary pressure

Figure 15: Yield surfaces in $p-q-p_{c}$ space -a) Cross section in $p-p_{c}$ plane -b) Cross section in $p-$ q plane

Figure 16: Position of the Critical State Line (CSL) in the p-q plane 
Figure 17: Parameters used in the Van Genuchten equation (Equation 16)

Figure 18: a) Gas pressure - mean net stress relationship b) Capillary pressure - mean net stress relationship for unsaturated soil

Figure 19: Shear stress-shear strains relationships under undrained conditions for an unsaturated soil 

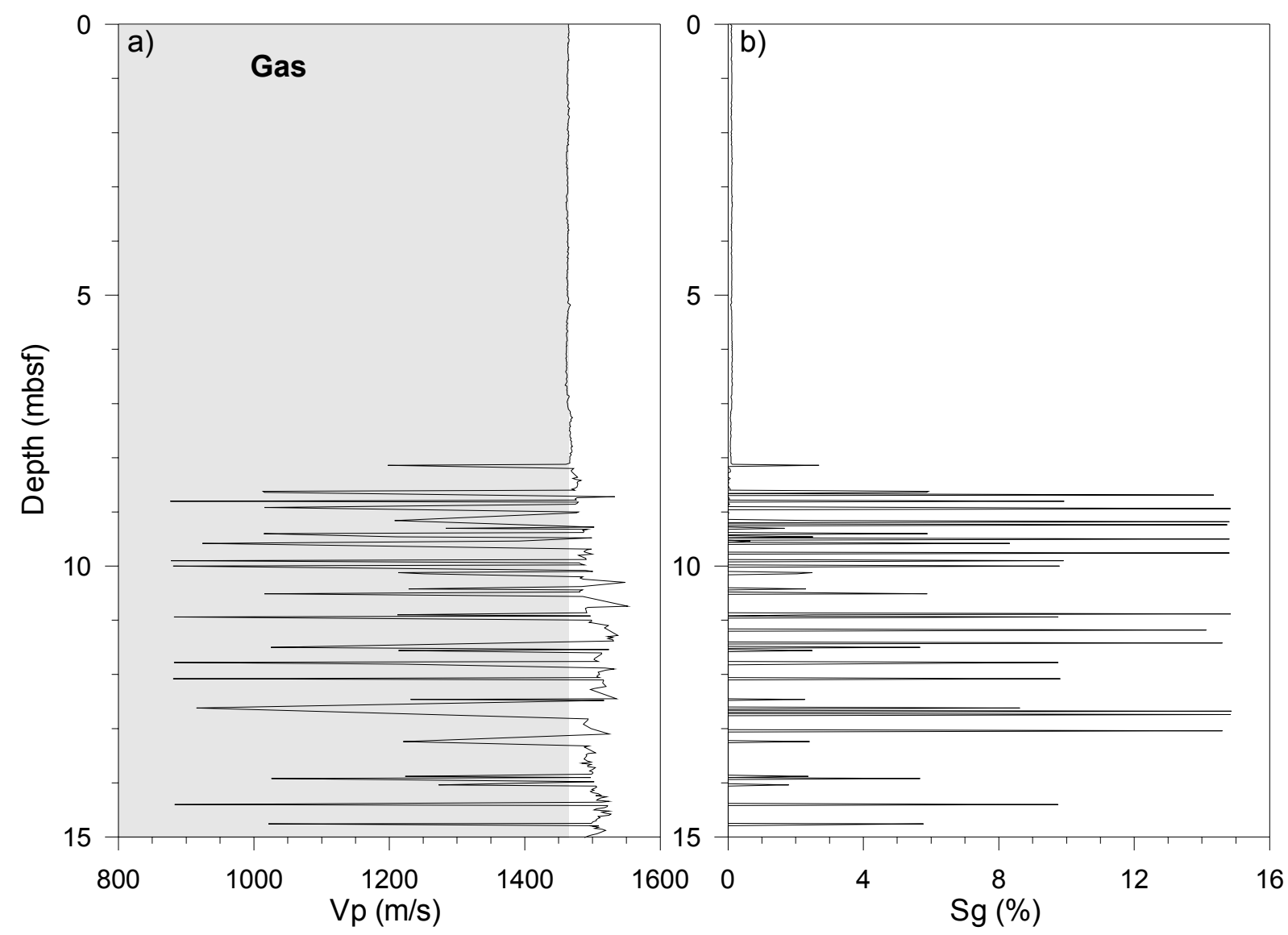

Figure 1: a) In-situ measurement of the $P$ wave velocity as a function of depth $b$ ) gas degree of saturation (Sg) calculated from the $P$ wave velocity profile using the effective medium theory (Helgerud et al. 1999). 

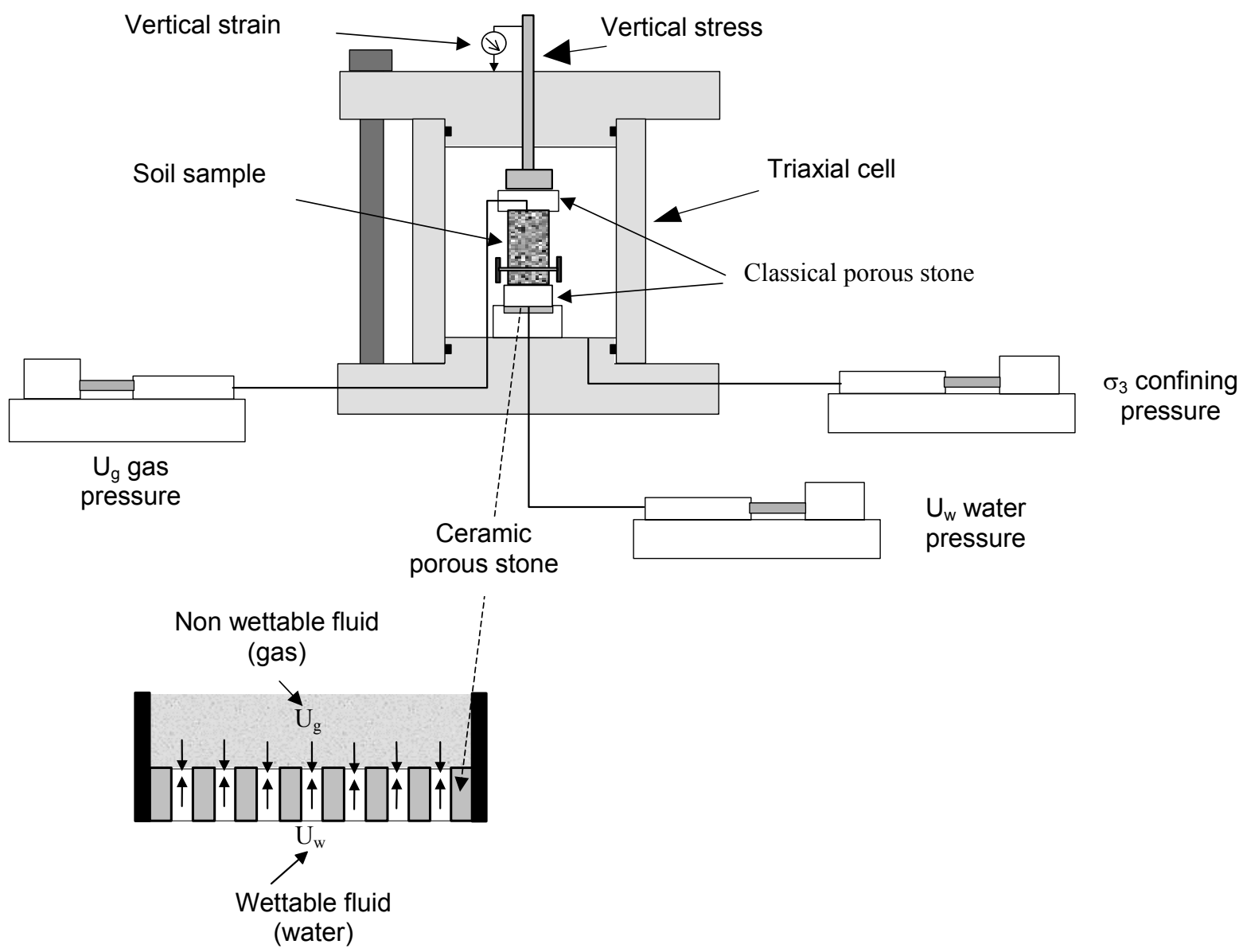

Figure 2: Triaxial cell for unsaturated soil 


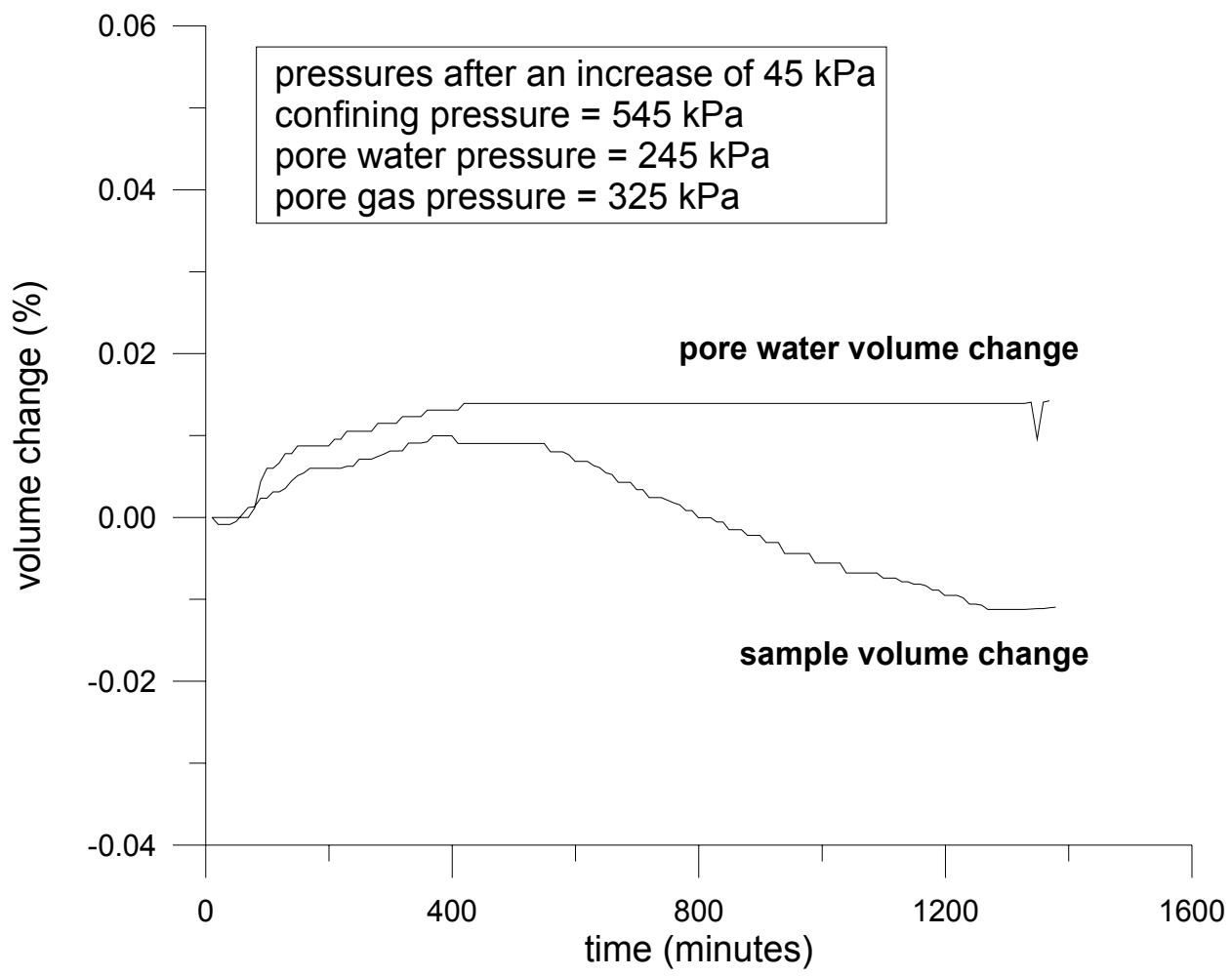

Figure 3: Result from NT1 Test 


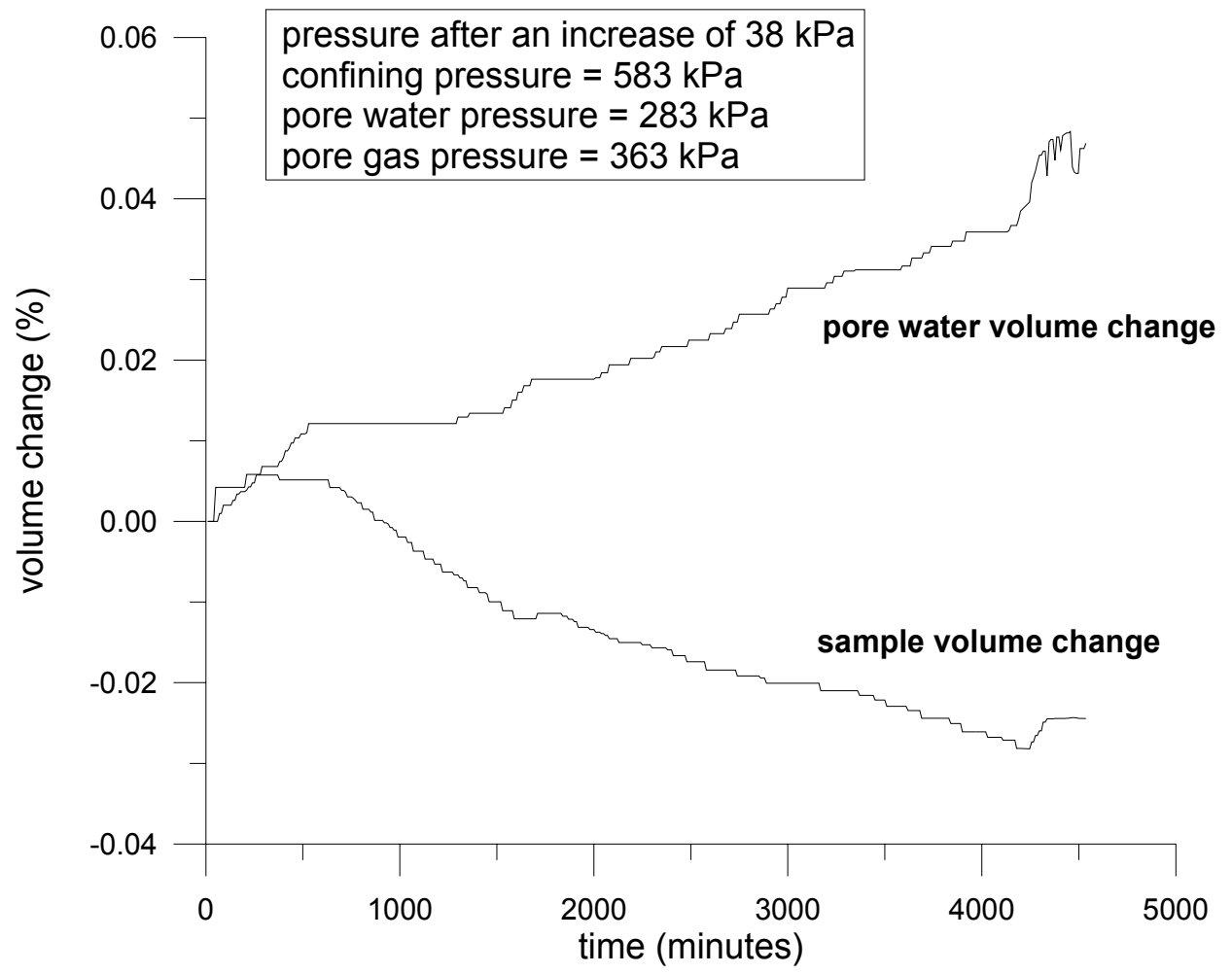

Figure 4: Result from NT2 Test 


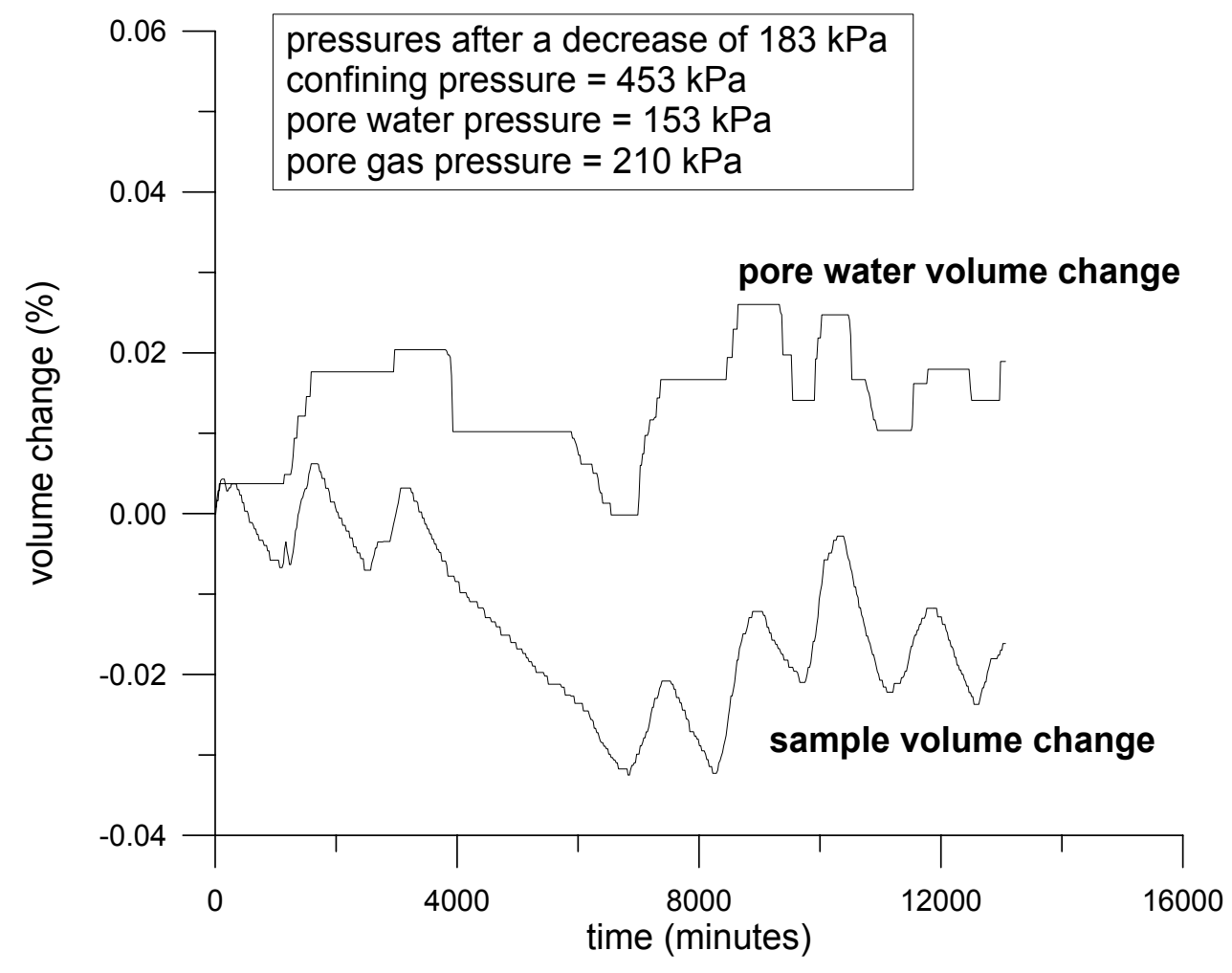

Figure 5: Result from NT3 Test 


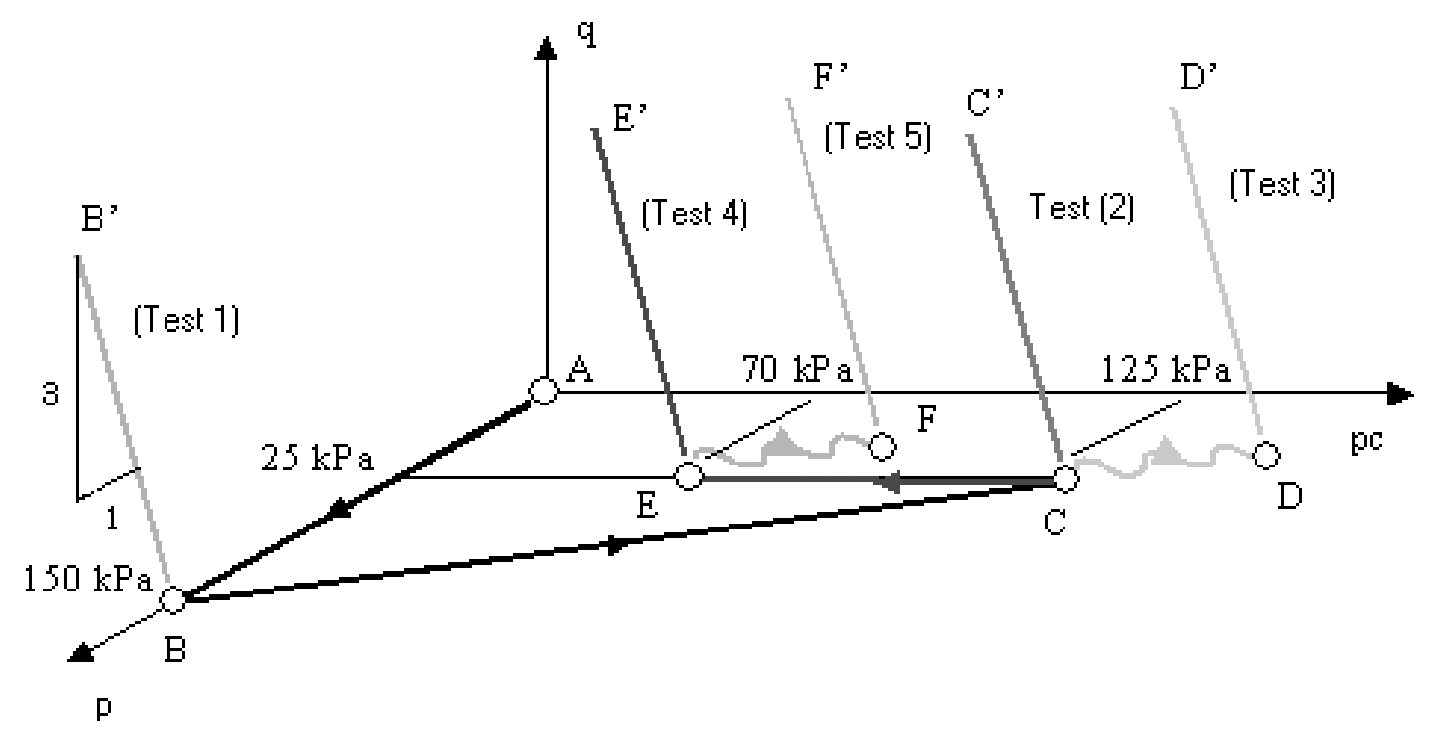

Figure 6: Stress paths for the five experimental tests 


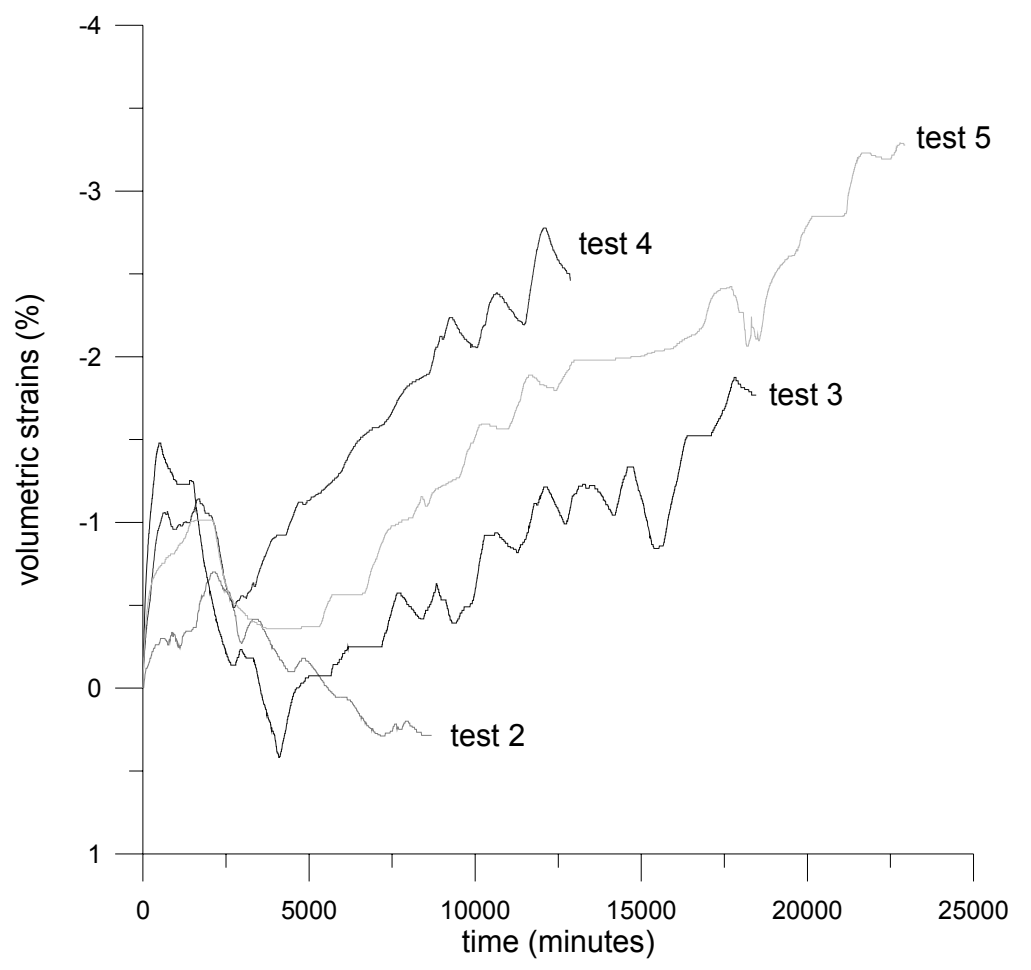

Figure 7. Volumetric strains - time diagram during application of the gas pressure (path B-C in Figure 6) 


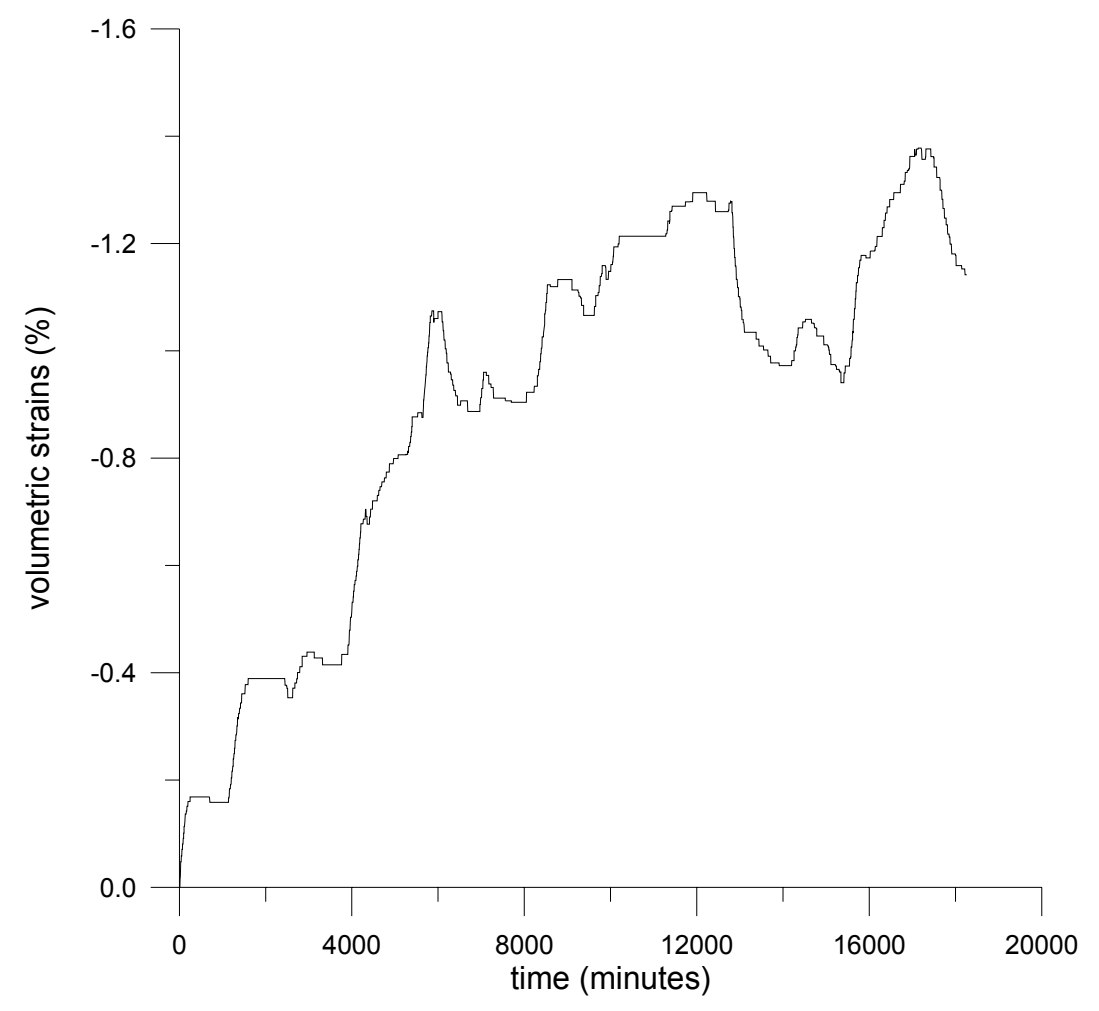

Figure 8: Volumetric strains during capillary pressure decreasing for test 5 (path C-E in Figure 6) 


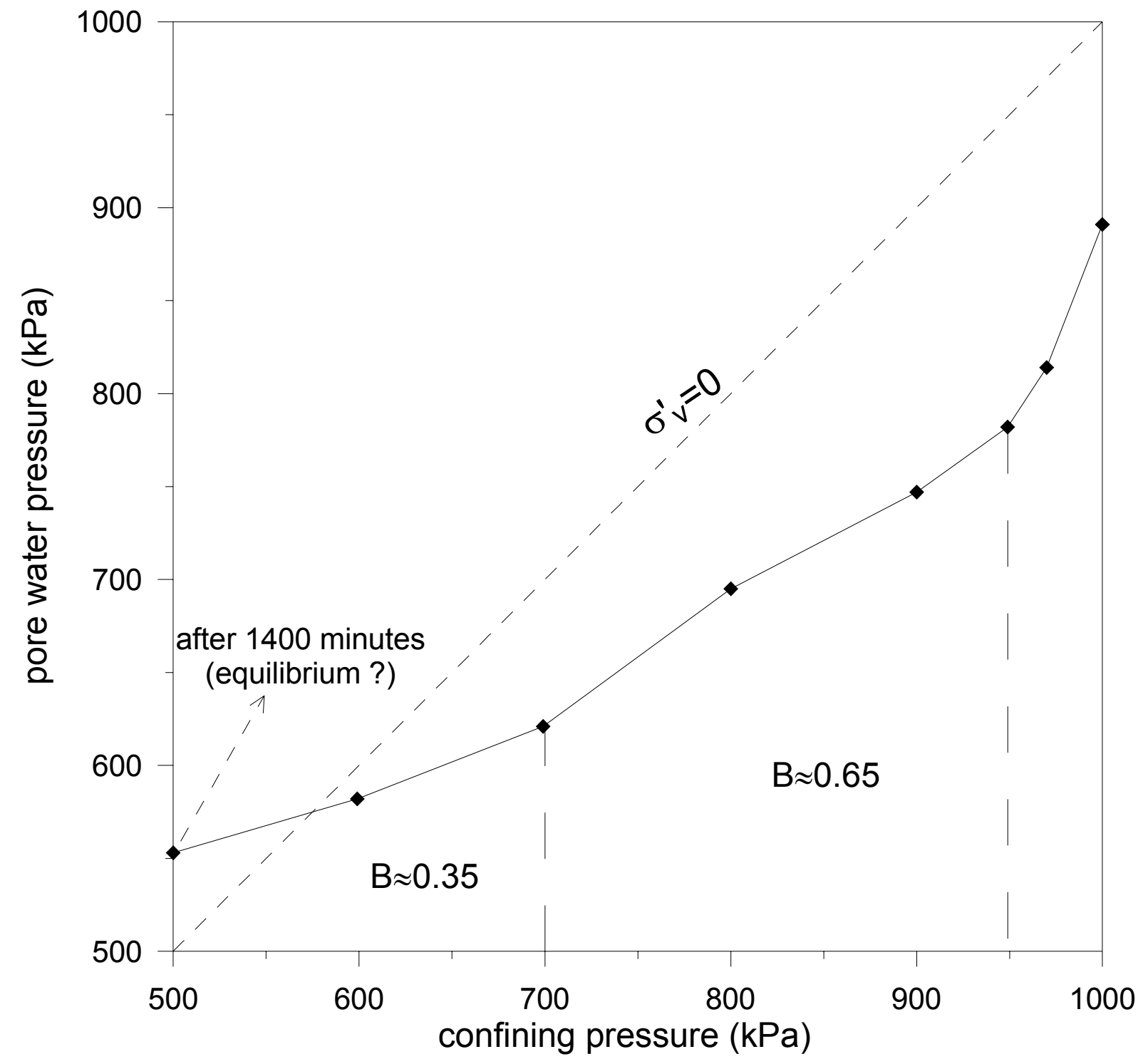

Figure 9: Evolution of pore water pressure as a function of the confining pressure during unloading at constant water content (test 5, from $\mathbf{E}$ to $\mathrm{F}$ in Figure 6) 


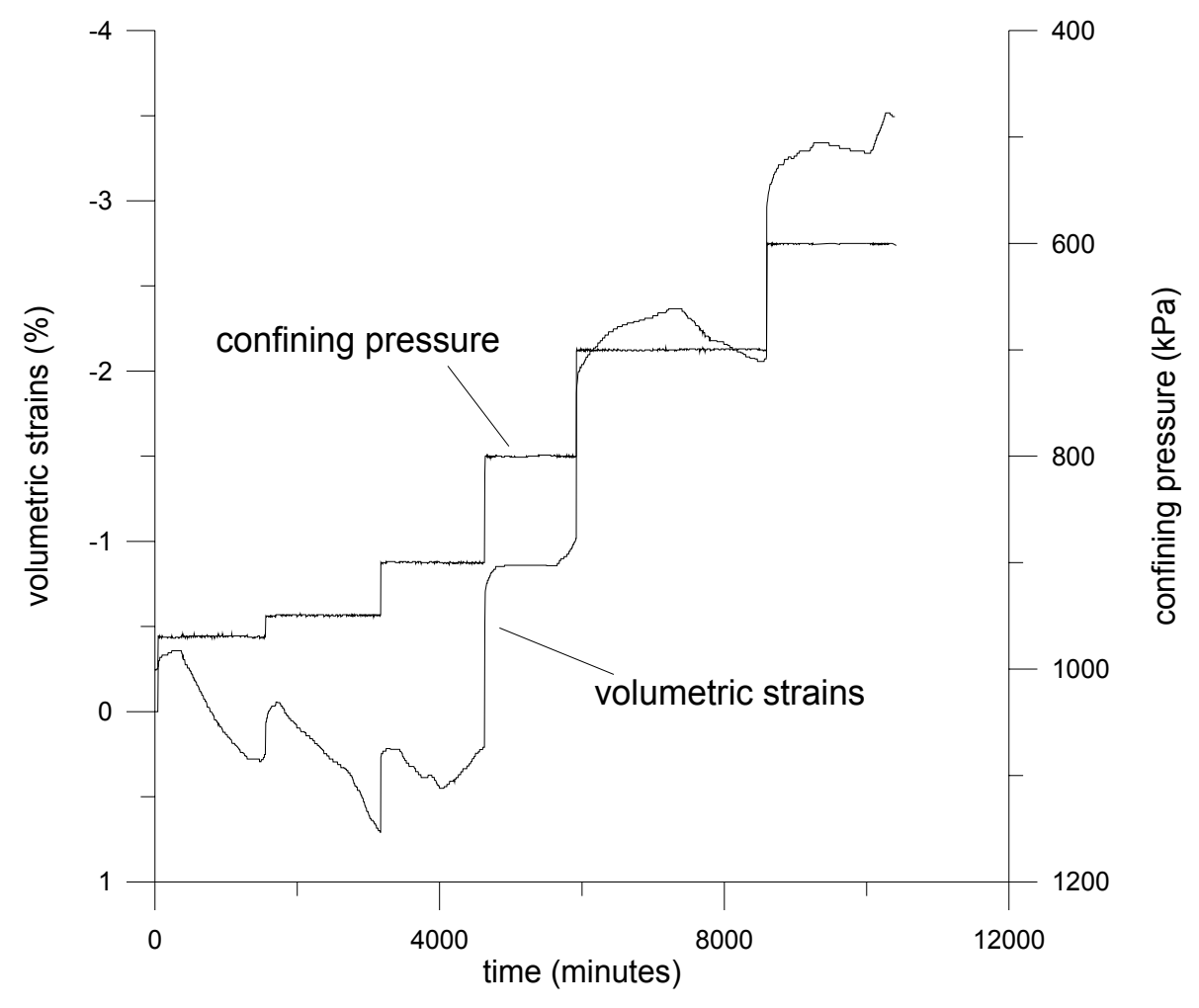

Figure 10: Volumetric strains and confining pressure versus time for different unloading steps at constant water content 


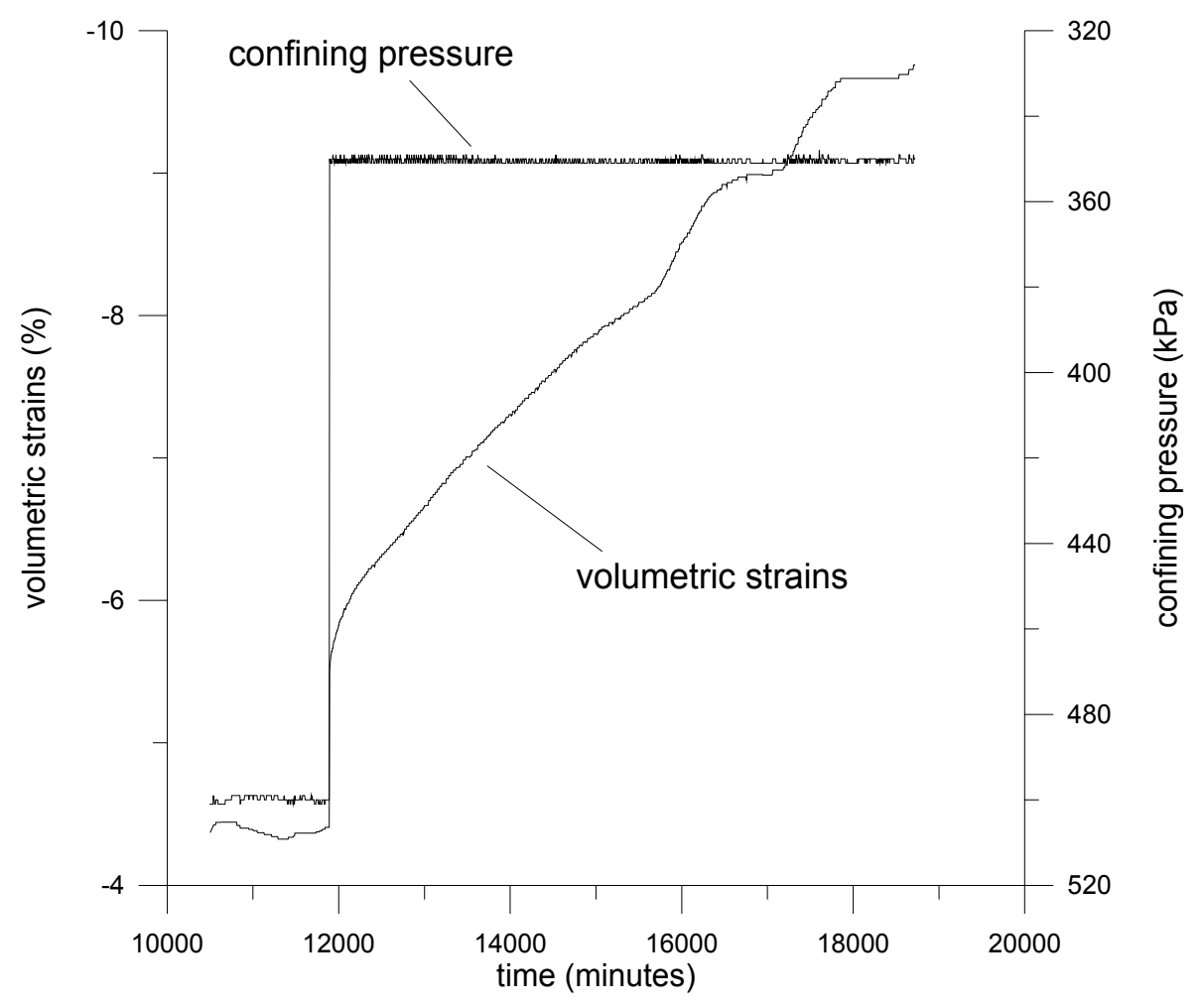

Figure 11: Volumetric strains and confining pressure versus time generated by a decrease of the confining pressure from $600 \mathrm{kPa}$ to $350 \mathrm{kPa}$ at constant water content 

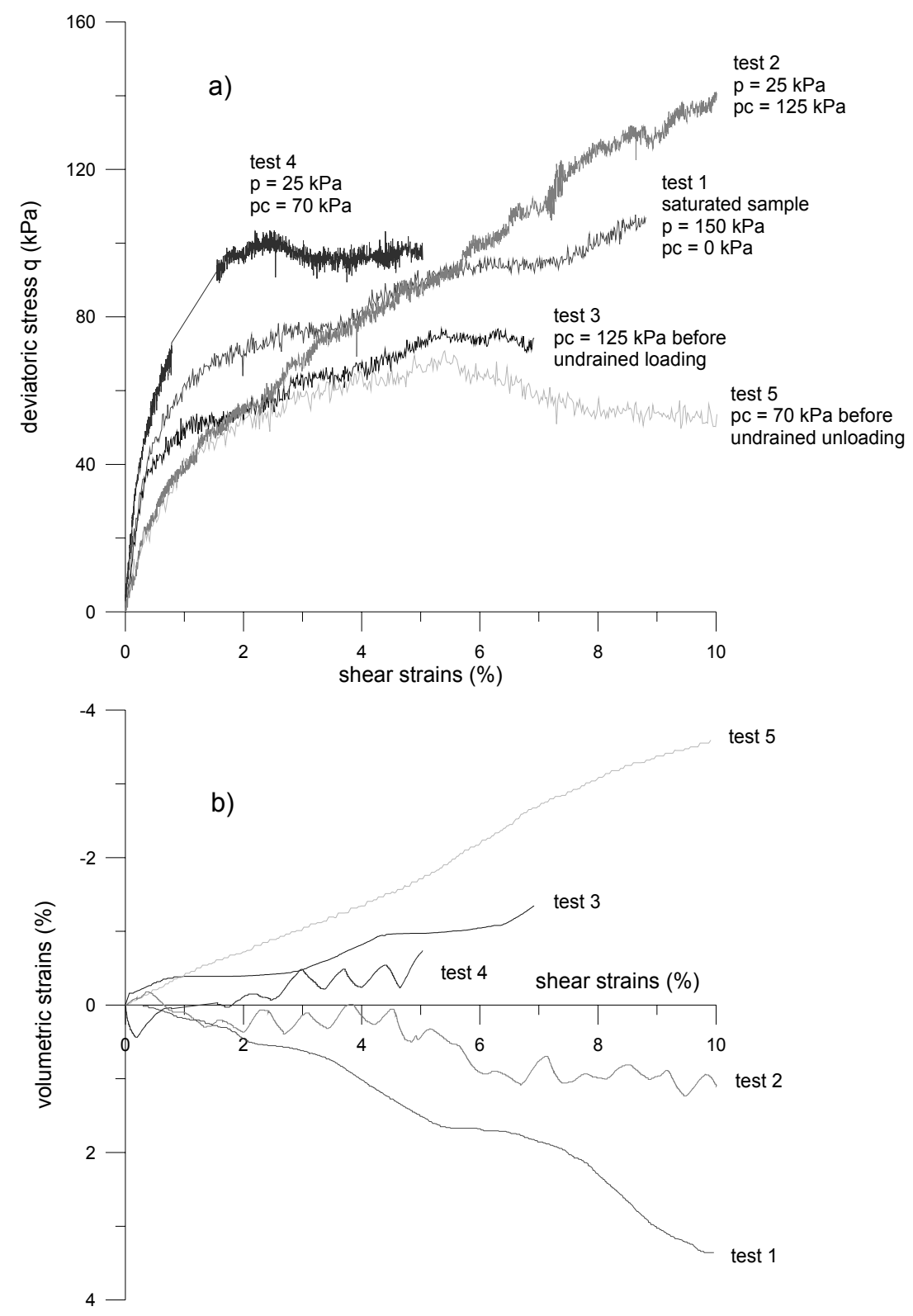

Figure 12: a) Deviatoric stress - shear strains diagram b) Volumetric strains - shear strains diagram 


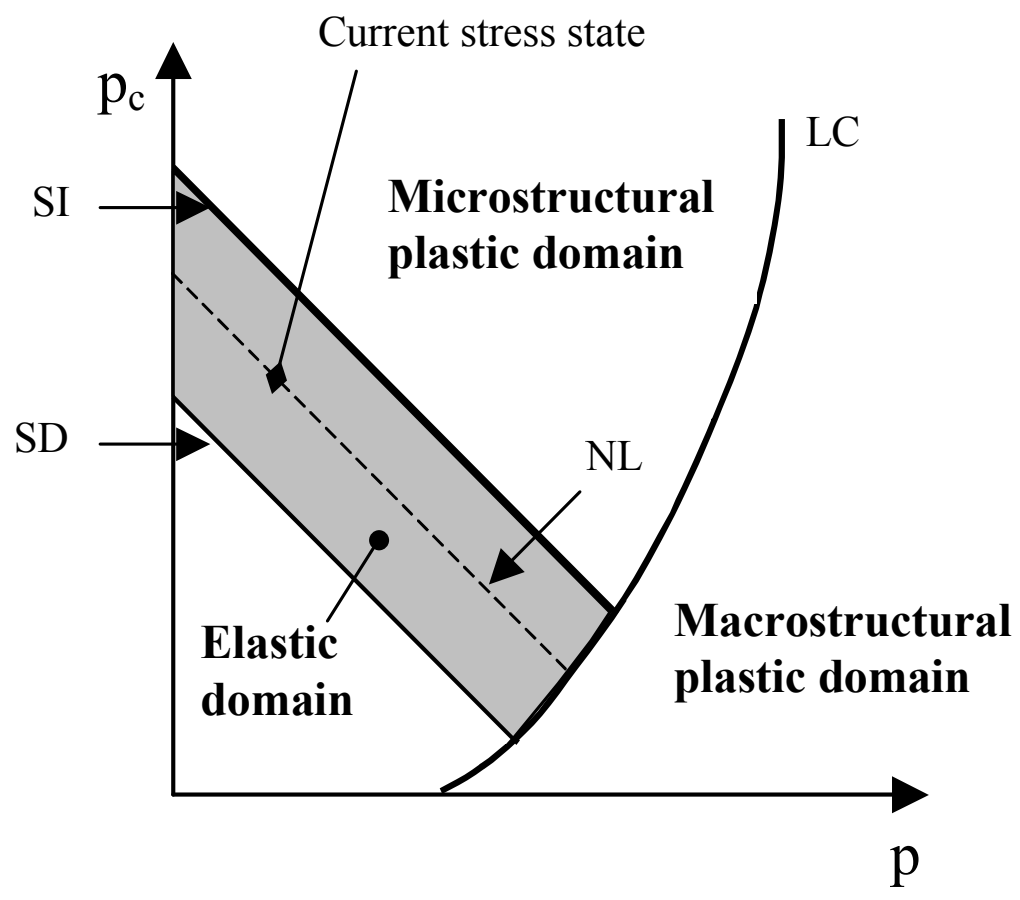

Figure 13: Yield loci in $p-p_{c}$ plane (after Gens and Alonso 1992) 


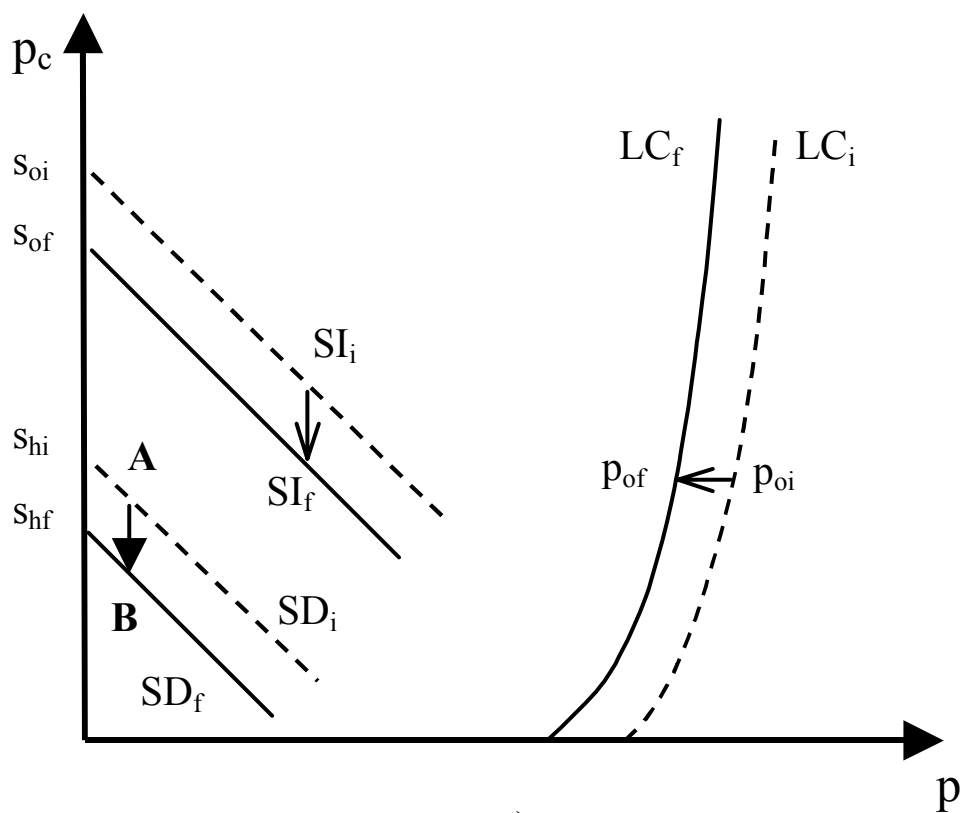

a)

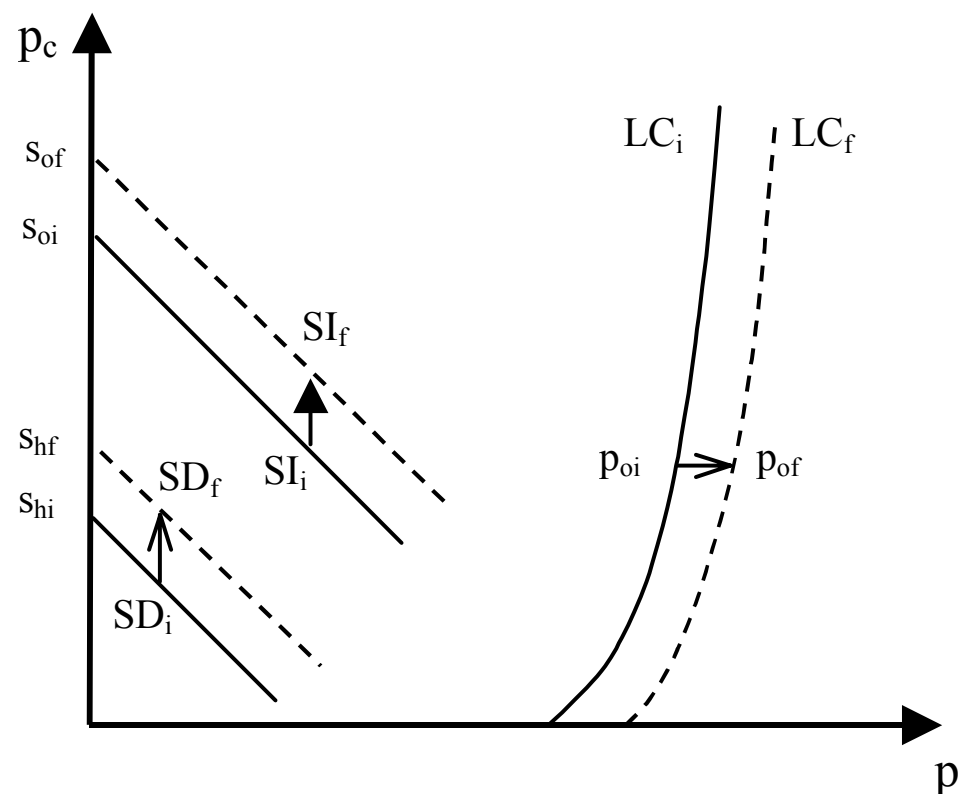

b)

Figure 14: Coupling between microstructural and macrostructural yield curves a) With a decrease of capillary pressure - b) With an increase of capillary pressure (after Gens and Alonso. 1992) 


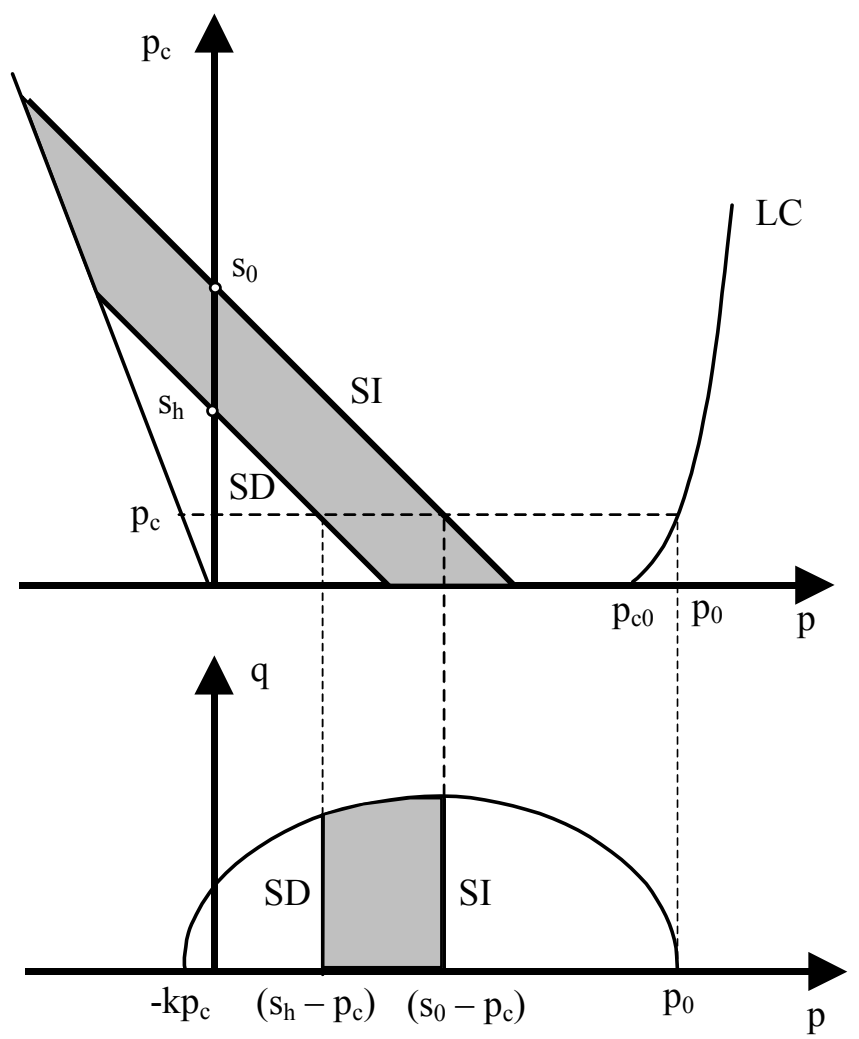

Figure 15: Yield surfaces in $p-q-p_{c}$ space -a) Cross section in $p-p_{c}$ plane -b) Cross section in $p-q$ plane (after Gens and Alonso. 1992) 


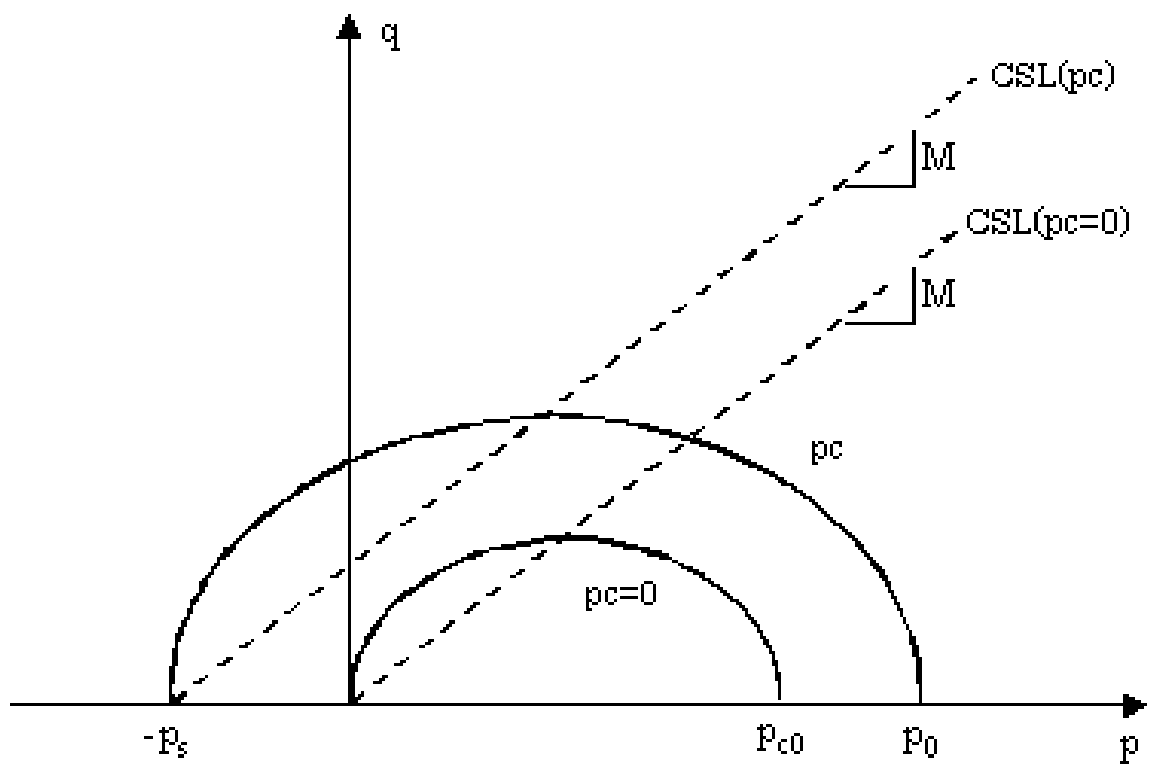

Figure 16: Position of the Critical State Line (CSL) in the p-q plane 


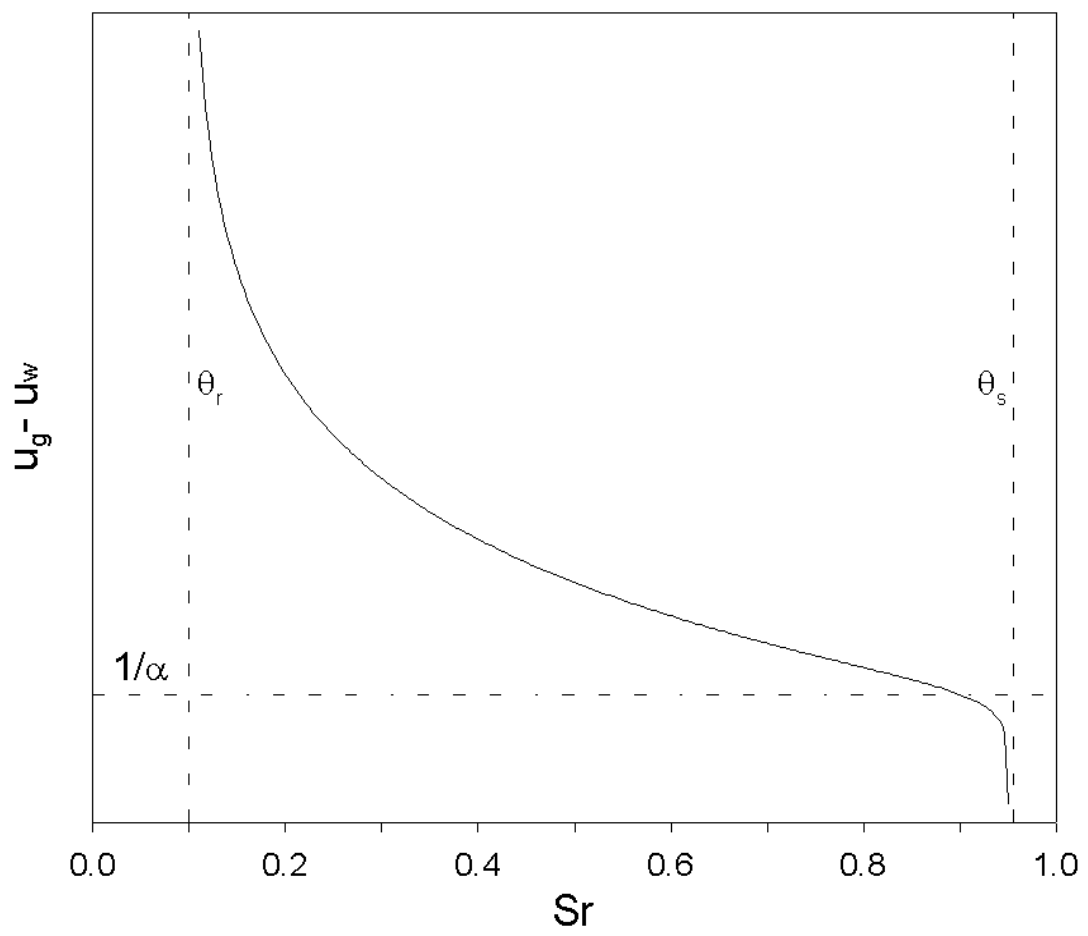

Figure 17: Parameters used in the Van Genuchten equation (Equation 16) 
a)

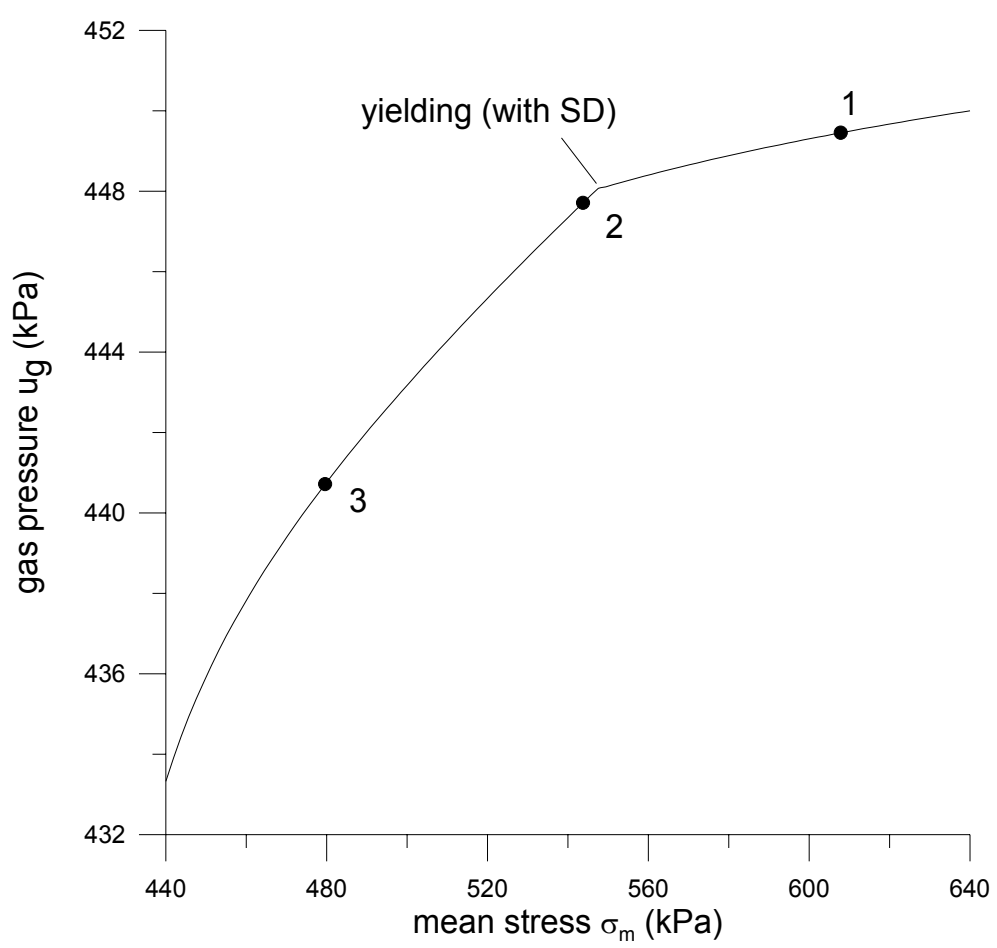

b)

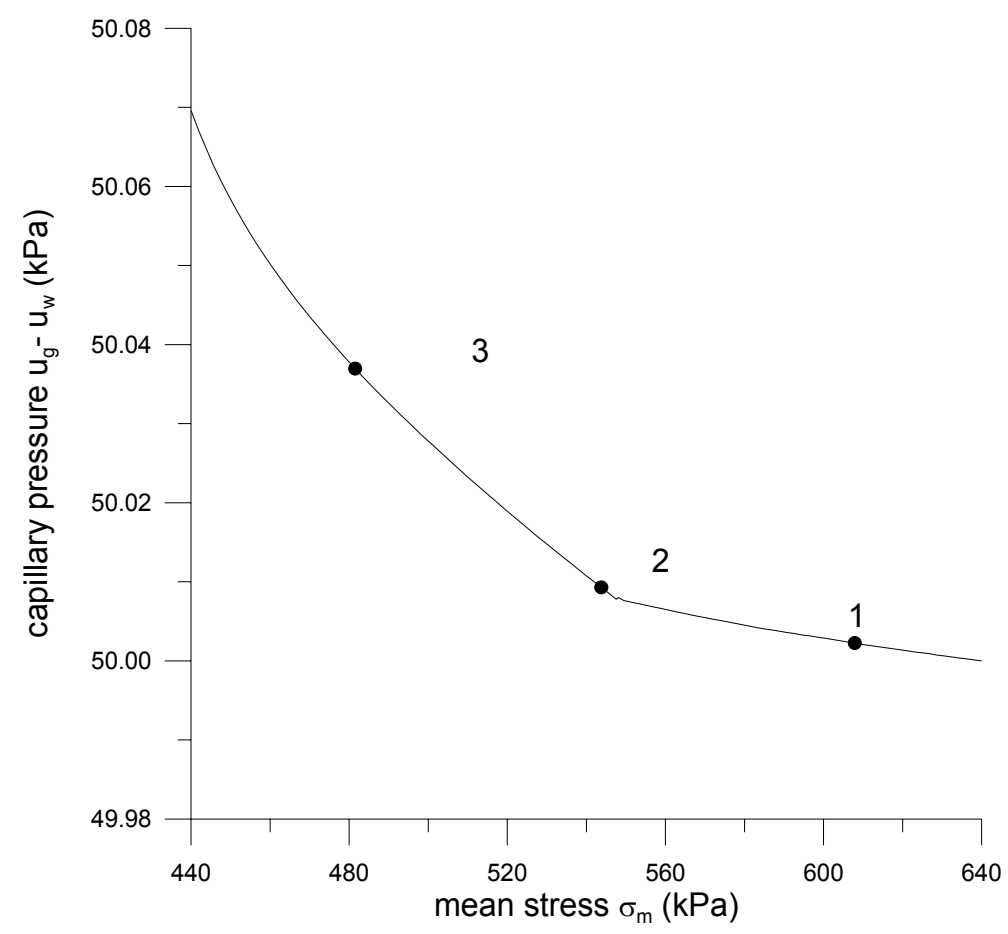

Figure 18: a) Gas pressure - mean net stress relationship b) Capillary pressure - mean net stress relationship for unsaturated soil 


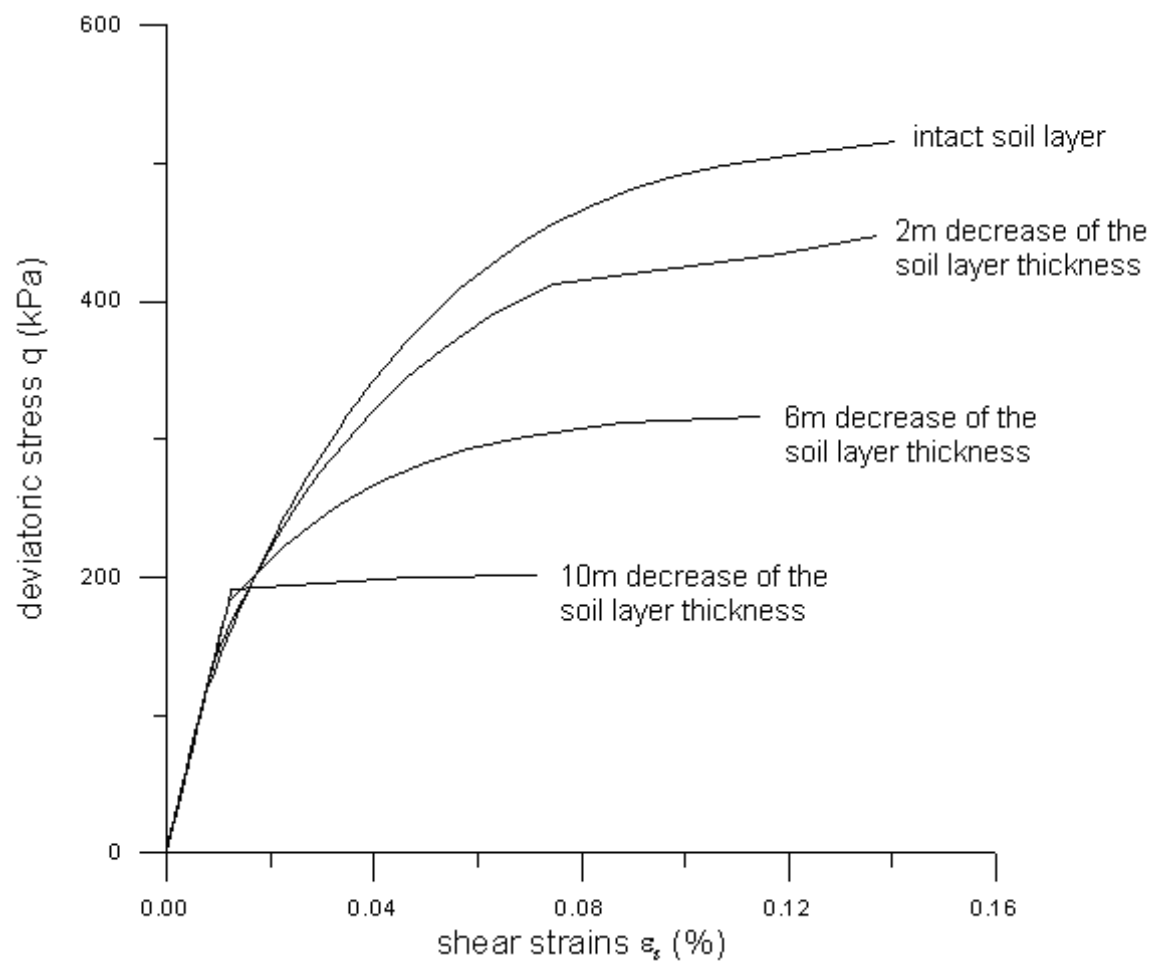

Figure 19: Shear stress-shear strains relationships under undrained conditions for an unsaturated soil 